\title{
ALTERATIONS IN NEURAL CELL ADHESION MOLECULES DURING DEVELOPMENT OF DIFFERENT REGIONS OF THE NERVOUS SYSTEM $^{1}$
}

CHENG-MING CHUONG AND GERALD M. EDELMAN ${ }^{2}$

Laboratory of Developmental and Molecular Biology, The Rockefeller University, New York, New York 10021

Received January 30, 1984; Accepted March 20, 1984

\begin{abstract}
Several cell adhesion molecules involved in neuron-neuron and neuron-glia interactions have been identified in our laboratory and have been shown to undergo cell surface modulation. In the case of the neural cell adhesion molecule (N-CAM), it has been found that during development the molecule is converted from a microheterogeneous embryonic (E) form containing $30 \mathrm{gm}$ of sialic acid/100 gm of polypeptide to several distinct adult (A) forms containing one third as much of this sugar. In vitro analyses indicate that this change is accompanied by a 4 -fold increase in the rate of N-CAM homophilic binding. In the present study of the mouse and the chick, alterations of $\mathrm{N}$-CAMs occurring as a result of $\mathrm{E} \rightarrow \mathrm{A}$ conversion, prevalence modulation, and changes in antigenic state during the development of different neural regions were analyzed by the use of highly specific polyclonal and monoclonal antibodies combined with anatomical dissection and several new quantitative assays. We made the following observations. (1) The relative concentration of N-CAM changed during development, with the highest concentration (2.8 times the adult level) occurring around the perinatal period. Each brain region followed a similar pattern of change but according to a different time schedule. (2) While conversion from the $\mathrm{E}$ to the $\mathrm{A}$ forms of N-CAM occurred mainly during the first 3 postnatal weeks in mice, the relative conversion rates were distinctly different in various neural tissues. The extreme examples are dorsal root ganglia, which already displayed the A forms at birth, and the diencephalon and tectal region, which still retained some $\mathrm{E}$ forms in the adult. (3) A cephalocaudal maturation gradient of $\mathrm{E} \rightarrow \mathrm{A}$ conversion was observed in the spinal cord and dorsal root ganglia. (4) Differences in the antigenic determinants of $\mathrm{N}$-CAMs from different neural tissues were detected by two independent monoclonal antibodies. (5) Finally, in some adult neural tissues, one of the three A forms was found to be dominant.

These results establish that during development there are definite quantitative and qualitative differences among N-CAMs from various neural tissues. The data are consistent with the hypothesis that alterations in the relative amounts and forms of $\mathrm{N}$-CAM play major roles in neural morphogenesis, possibly by altering the rates of adhesion among neurons and their processes.
\end{abstract}

Previous studies in this laboratory have led to the identification of a series of cell adhesion molecules of different specificity (for a review, see Edelman, 1983). The earliest of these to be identified unequivocally was the neural cell adhesion molecule (N-CAM), which mediates neuron-neuron interaction throughout the nervous system (Brackenbury et al., 1977; Rutishauser et al., 1978) as well as neuron-myotube interactions (Grumet et al., 1982). Alteration in N-CAM expression has also been found to be associated with neural induction and secondary inductions in embryogenesis; during these events N-CAM and another adhesion molecule originally isolated from liver (L-CAM) undergo major changes in prevalence at the cell surface (Thiery et al., 1982; Edelman et al., 1983). At later

\footnotetext{
${ }^{1}$ We thank Ms. Alison Schroeder and Ms. Susan B. Hyman for excellent technical assistance. We are grateful to Dr. W. Einar Gall and Dr. George N. Reeke, Jr. for their help with densitometric gel scans. This work was supported by United States Public Health Service Grants HD-16550, HD-09635, and AI-11378.

${ }^{2}$ To whom correspondence should be addressed.
}

embryonic periods, N-CAM is involved in major histogenetic shaping in the nervous system (see, for example, Buskirk et al., 1980). Recently, another cell adhesion molecule, $\mathrm{Ng}$-CAM, that is involved in neuron-glia interaction, has also been identified (Grumet et al., 1984). All of this work suggests that these cell adhesion molecules may play major roles in embryonic development by means of cell surface modulations (Edelman, 1983) and controlled interactions.

Different chemical forms of N-CAM have been found in embryonic and adult chicken brains (Rothbard et al., 1982). $\mathrm{N}$-CAM purified from embryonic brains (embryonic or $\mathrm{E}$ form) has a high content of sialic acid ( $30 \mathrm{gm} / 100 \mathrm{gm}$ of polypeptide) and migrates as a broad diffuse band of $M_{\mathrm{r}}=180,000$ to 250,000 in sodium dodecyl sulfate-polyacrylamide gel electrophoresis (SDS-PAGE) (Hoffman et al., 1982). In contrast, N-CAM from adult brains (adult or A forms) has only one third this amount of sialic acid and migrates as two distinct electrophoretic bands of $M_{r}=180,000$ and 150,000 . The mouse brain also contains N-CAM (Chuong et al., 1982) and displays $\mathrm{E}$ and $\mathrm{A}$ forms (Edelman and Chuong, 1982; Rougon et al., 1982) which ap- 
peared as three distinct bands of $M_{\mathrm{r}}=180,000,140,000$, and 120,000 in electrophoretic gels. We refer to this age-dependent change of N-CAM from the embryonic form to the adult forms as $\mathrm{E} \rightarrow \mathrm{A}$ conversion (Edelman and Chuong, 1982).

The full functional significance and mechanism of the $\mathrm{E} \rightarrow \mathrm{A}$ conversion in vivo are not yet understood. In the charge perturbation model of N-CAM binding (Edelman, 1983), it was suggested that the sialic acid-rich sugar moiety may perturb the homophilic binding of N-CAMs on adherent cells via repulsion, induction of conformational change, or redistribution of molecules on the cell surface. $\mathrm{E} \rightarrow \mathrm{A}$ conversion, which removes large amounts of sialic acid, would thus be expected to lead to an enhancement of CAM-CAM binding. A failure in $\mathrm{E} \rightarrow \mathrm{A}$ conversion in vivo might therefore lead to a failure in the formation or stabilization of appropriate neural connections. In staggerer mutants of mice, $\mathrm{E} \rightarrow \mathrm{A}$ conversion of N-CAM is delayed in the cerebellum (Edelman and Chuong, 1982), raising the possibility that some of the histogenetic defects in the cerebellum of such animals might be related to a failure to produce the A forms of N-CAM at the proper time. This interpretation is further supported by recent experiments using reconstituted vesicles containing only purified N-CAMs and lipids: the vesicles containing the A forms of N-CAM aggregated 4 -fold more rapidly than the vesicles containing the $\mathrm{E}$ form of $\mathrm{N}$-CAM. Moreover, vesicles containing twice the amount of N-CAM aggregated with a 30 -fold increase in rate (Hoffman and Edelman, 1983). These data suggest that differences in adhesivity in vivo and consequent effects on neural patterning could be produced by means of quantitative and qualitative modulation of N-CAM at the cell surface.

In order to lay a foundation for further assessment of the in vivo role of alterations of N-CAM, we have analyzed the time course of $\mathrm{E} \rightarrow \mathrm{A}$ conversion as well as the changes in N-CAM concentration in the whole brain and in different neural regions. Because the brain is composed of different neuronal populations, it is conceivable that the rates of $\mathrm{E} \rightarrow \mathrm{A}$ conversion, the time course of changes in concentration, and the proportions of the forms of N-CAM may differ in various neural regions. Previous observations (Edelman and Chuong, 1982) have shown that the relative rates of conversion differ in three brain regions in the order: cerebellum $>$ parietal cortex $>$ hippocampus. In the present investigation, we have examined in much greater detail the forms of N-CAM that are present during mouse, rat, and chick development in a large variety of neural regions, using rabbit anti-N-CAM antibodies and a monoclonal antibody (MAb) 15G8 which is specific for the $\mathrm{E}$ form of N-CAM (Chuong et al., 1982). Quantitation of the N-CAM present in various neural tissues has also been carried out. The combined data indicate that there are significant variations in both the amounts and the forms of N-CAM from various neural regions as well as during different developmental stages.

\section{Materials and Methods}

Animals and neural tissue lysates. NCS (Swiss) mice from the Laboratory Animal Research Center of The Rockefeller University were used for most of the experiments. For experiments with aged mice, C57BL/6 mice obtained from the National Institute on Aging were used.

Mice were killed by decapitation, and the brains were removed and immersed in ice-cold $\mathrm{Ca}^{2+} / \mathrm{Mg}^{2+}$-free medium (Takeichi, 1977) containing Trasylol (200 KIU/ml; FBA Pharmaceuticals) and phenylmethylsulfonyl fluoride (PMSF, $1 \mathrm{mM}$ ). Various neural regions were dissected under a Wild stereomicroscope according to descriptions in the atlas by Sidman et al. (1971). As defined here, cerebral cortex includes the cortex of the cerebral hemisphere that lies above the rhinal fissure. The region designated "tectum" includes both superior and inferior colliculi. The region designated "hippocampus" includes the dentate gyrus. In the experiments with spinal cord and dorsal root ganglia, C2 and C3 were dissected as representive of cervical spinal cord and ganglia, T9 and T10 as representive of the thoracic region, and L4 and $\mathrm{L} 5$ as representative of the lumbar region.

Chickens or chick embryos (White Leghorn) were sacrificed at the designated ages. Chick retinas were dissected either as a whole or into eight portions; in the latter case, the four portions from several animals corresponding to the anterior, posterior, dorsal, and ventral positions were pooled separately. Tecta were dissected into five portions along anterior-posterior or medial-lateral axes and each portion was analyzed separately.

The dissected neural tissues were homogenized in ice-cold phosphate-buffered saline (PBS) $/ 0.5 \%$ Nonidet P40/EDTA (1 mM)/Trasylol $(200 \mathrm{KIU} / \mathrm{ml}) /$ PMSF $(1 \mathrm{mM})$. The samples were treated in a vortex mixer and left in ice for $5 \mathrm{~min}$; then they were centrifuged in a Microfuge (Beckman Instruments, $10 \mathrm{~kg}$ ) for $10 \mathrm{~min}$. The protein concentrations of the lysate supernatants were determined by the BioRad assay (Bradford, 1976) with protein standards adjusted to contain the same amount of Nonidet P40 as the samples. These lysates were then used for gel electrophoresis and for quantification of N-CAM.

Immunoblots. The antibodies used in this study were produced as described previously (Chuong et al., 1982). They included rabbit antiN-CAM polyclonal antibodies and the mouse MAbs 15G8 (IgM), 9E11 $\left(\operatorname{IgG}_{2 s}\right)$, and anti-(N-CAM) No. 5 (IgM). Immunoblots were performed according to the method of Towbin et al. (1979). The brain lysates were resolved by electrophoresis on $7.5 \%$ SDS polyacrylamide gels and were electrophoretically transferred to nitrocellulose paper (Schleicher and Schuell BA 85) at $12 \mathrm{~V}$ for $3 \mathrm{hr}$. The electrophoretic transfer buffer was the same as the PAGE running buffer but contained $20 \%$ methanol in addition.

Transferred proteins were visualized by staining the nitrocellulose paper with amido black solution $(0.1 \%$ in $45 \%$ methanol $/ 10 \%$ acetic acid $/ 45 \% \mathrm{H}_{2} \mathrm{O}$ ) for $5 \mathrm{~min}$ and destaining with $90 \%$ methanol $/ 2 \%$ acetic acid $/ 8 \% \mathrm{H}_{2} \mathrm{O}$. The nitrocellulose paper blot was then immersed in 30 $\mathrm{mg} / \mathrm{ml}$ of crude ovalbumin (Sigma) $/ 0.1 \%$ Triton X-100/10 mM Tris$\mathrm{HCl}, \mathrm{pH} 7.2 / 0.9 \% \mathrm{NaCl} / 0.1 \% \mathrm{NaN}_{3}$ for $2 \mathrm{hr}$ to block nonspecific protein-binding sites. Antibodies were then added to the above mixture to a final concentration of $3 \mu \mathrm{g} / \mathrm{ml}$ of IgG. After incubation overnight, each blot was washed six times for 10 -min periods with $0.1 \%$ Triton $\mathrm{X}-100 / 10 \mathrm{~mm}$ Tris $\mathrm{HCl}, \mathrm{pH} 7.2 / 0.9 \% \mathrm{NaCl} / 0.1 \% \mathrm{NaN}_{3}$. When monoclonal antibodies were used, rabbit anti-mouse immunoglobulin antibodies $(6 \mu \mathrm{g} / \mathrm{ml})$ were added as secondary antibody. Finally, the blot was reimmersed in the above blocking solution, and $7 \times 10^{4} \mathrm{cpm} / \mathrm{ml}$ of $\left[{ }^{125}\right.$ I]protein $A$ was added to bind to antibodies that had reacted with proteins on the blot. After washing, the results were visualized by autoradiography.

Quantitative measurement of $N$-CAM. Three methods were used to quantitate the amount of N-CAM in different neural tissues: $(a)$ cutting out and counting areas of the gel blots that reacted with radioactive protein A in a gamma counter; $(b)$ performing densitometric scans of autoradiographs of the gel blots; and $(c)$ using an enzyme-linked immunosubstrate assay (ELISA). To count the gel blots, areas of the nitrocellulose corresponding to range bounded by apparent $M_{\mathrm{r}}=$ 100,000 to 250,000 were cut out and counted in a gamma counter for $10 \mathrm{~min}$. A similar portion of nitrocellulose paper from the same gel blot was counted to represent the background.

The densitometric scans were performed and analyzed as described previously (Edelman and Chuong, 1982). N-CAM standards were carried in the same gel as the tissue lysates.

ELISA was performed by incubating N-CAM or tissue lysates in 50 $\mu \mathrm{l}$ of buffer A (PBS, $0.5 \%$ Nonidet P40, and $1 \mathrm{mg} / \mathrm{ml}$ of bovine serum albumin) with 96 -well polyvinyl plates. The incubation was performed at $37^{\circ} \mathrm{C}$ until the plates were dry. The plates were then fixed for $5 \mathrm{~min}$ with methanol, dried again, then incubated at room temperature with buffer B (buffer A with bovine serum albumin supplemented up to 10 $\mathrm{mg} / \mathrm{ml})$ for $1 \mathrm{hr}$, followed by the rabbit anti-N-CAM antibody ( $1 \mu \mathrm{g}$ in $50 \mu \mathrm{l}$ of buffer B) overnight. On the next day, the plates were washed five times with buffer A, preincubated with buffer $B$ again, and then incubated with biotinylated goat anti-rabbit antibody (Vector) for another $2 \mathrm{hr}$. After washing, avidin-biotin-peroxidase complex was added to the wells, and the bound peroxidase was developed using $O$ phenylenediamine as substrate $(1 \mathrm{mg} / \mathrm{ml}$ in $0.1 \mathrm{M}$ citrate buffer, $\mathrm{pH}$ 4.5 , containing $0.012 \% \mathrm{H}_{2} \mathrm{O}_{2}$ ); the results were recorded as optical density at $488 \mathrm{~nm}$.

For each determination, a 1:2 dilution series of the tissue lysates (starting from a concentration of $10 \mu \mathrm{g}$ of protein/well) was used. The resultant optical density values were then compared to the values from 
the standard curve which was composed of a $1: 2$ dilution series of purified embryonic mouse N-CAM (starting at $50 \mathrm{ng} /$ well).

For determination of N-CAM in membrane vesicles, brain membrane vesicles were prepared as described by Hoffman and Edelman (1983). Briefly, brain tissues were homogenized in $\mathrm{Ca}^{2+} / \mathrm{Mg}^{2+}$-free medium containing Trasylol and deoxyribonuclease. The homogenates were centrifuged $(10,000 \times g$ for $10 \mathrm{~min})$ and separated on a discontinuous sucrose density gradient. The membrane vesicles at the interface between $42 \%$ and $26 \%$ sucrose were removed, washed, and used for further analysis.

\section{Results}

The concentration of N-CAM changes during development and varies among different neural regions. Three methods were used to compare the concentration of N-CAM in various neural regions at different developmental ages. In the first method, the radioactivity associated with $\mathrm{N}-\mathrm{CAM}$ bands in gel blots was cut out and counted. Immunologically purified N-CAMs of various concentrations were processed in parallel. The resultant counts per minute were plotted against the various concentrations of tissue lysates and N-CAMs separately. These plots formed parallel lines over a wide range (Fig. $1 A$ ). The line for purified N-CAM was then used to calculate the amount of $\mathrm{N}$-CAM in tissue lysates.

The second method employed densitometric scans of autoradiographs obtained from the gel blot. Results of an N-CAM titration curve using this method are shown in Figure $1 A$. The densitometric values are linearly related to the amount of $\mathrm{N}$-CAM over the range from 50 to $1000 \mathrm{ng}$ of N-CAM; this plot was parallel to the line representing the radioactive counts from the original gel blot. Similar results were obtained when serial dilutions of tissue lysates were used. Therefore, this $\mathrm{N}$-CAM standard curve was also used to calculate the amount of N-CAM in tissue lysates of N-CAM.

The third and most sensitive method was ELISA. To determine a standard curve, various amounts of purified E-form $\mathrm{N}$-CAM were assayed in 2 -fold serial dilutions. The amount of enzyme reaction product formed (shown as optical density) was linearly related to the amount of $\mathrm{N}$-CAM over the range from 0.5 to $10 \mathrm{ng}$ of N-CAM (Fig. $1 A$ ). The ELISA method therefore appeared to be approximately 100 times more sensitive than the other two methods. Serially diluted tissue lysates gave similar results: a linear relationship was obtained between 50 and $500 \mathrm{ng}$ of the lysate protein. Figure $1 B$ shows results obtained with lysates from 7-day olfactory bulb, hippocampus, and cerebellum. At each concentration tested, the relative amounts of N-CAM were olfactory bulb $>$ hippocampus $>$ cerebellum. Values in the middle of the linear portions were then used to calculate the amount of N-CAM in each brain region.

Comparison of the methods showed that, although less sensitive, the densitometric scan method was particularly useful for analyzing the relative proportions of the $\mathrm{E}$ form and three A forms of N-CAM. In addition, it required serial dilutions of $\mathrm{N}$-CAM to construct standard curves for every gel. In contrast, the ELISA method was about 100 times more sensitive than the gel blot, allowed analysis of a large number of different samples at the same time, and also permitted triplicate measurements as well as serial dilutions to be carried out with relative ease. Therefore, we used ELISA to determine the concentrations of N-CAM in different tissues at different developmental ages (Table I). To check the results, the concen-
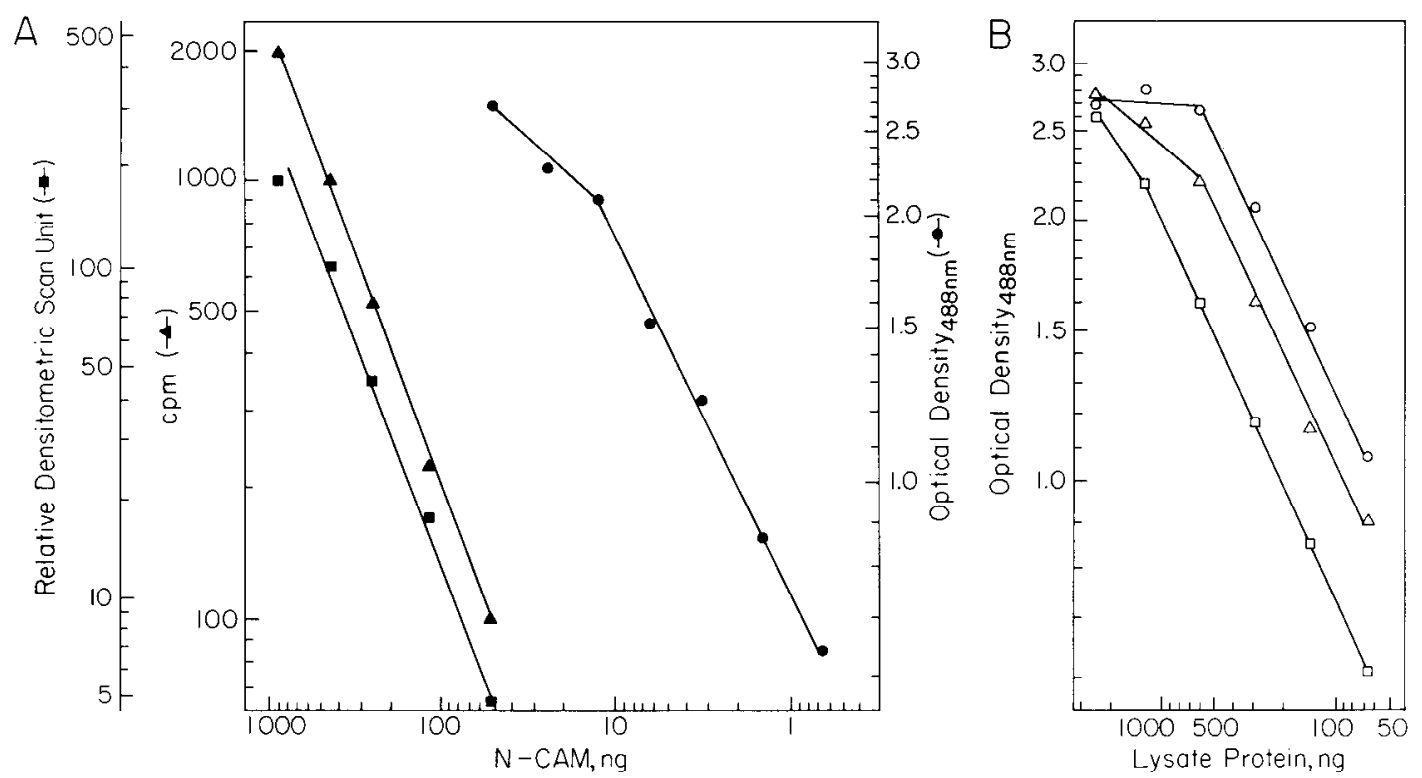

Figure 1. Quantitative measurements of N-CAM. A, Three methods were used: counting gel blots (A), densitometric scans of autoradiographs ( $\mathbf{0}$ ), and ELISA (-). Purified mouse N-CAM in various amounts (from 50 to $1000 \mathrm{ng}$, plotted on double log scales) was resolved in the gel, transferred to the gel blot, reacted with rabbit anti-N-CAM, and detected by [ $\left.{ }^{125} \mathrm{I}\right]$ protein $\mathrm{A}$. The gel blot was cut out and counted in a gamma counter (A) or used to produce autoradiographs which in turn were scanned densitometrically ( $\square$ ). Plots of values from the two methods resulted in two straight lines (counts per minute and densitometric units are plotted on log scales) which were parallel to each other. For the ELISA, different amounts of purified N-CAM (starting at 50 $\mathrm{ng}$, then with $1: 2$ serial dilutions down to $0.5 \mathrm{ng}$ ) were coated onto plastic plates and reacted with rabhit, anti$\mathrm{N}$-CAM, followed by biotinylated second antibody; bound antibodies were then visualized by avidin-biotinperoxidase complex and its substrate. The brown color reaction was recorded as optical density at $488 \mathrm{~nm}(\bullet)$ and plotted on a log scale. The linear region $(0.5$ to $10 \mathrm{ng})$ was used to calculate the amounts of N-CAM. $B$, Exemplary ELISA of tissue lysates from olfactory bulb $(O)$, hippocampus $(\triangle)$, and cerebellum $(\square)$ of 7 -day-old mice. Various amounts of tissue lysates (starting at $2250 \mathrm{ng}$, then diluted serially 1:2 down to $70 \mathrm{ng}$ ) were processed in the same way as in $A$. The results from three tissues formed three parallel lines over the range from $70 \mathrm{ng}$ to $562 \mathrm{ng}$, and the relative amounts of N-CAM were olfactory bulb $>$ hippocampus $>$ cerebellum. 
tration of N-CAM in some regions was also determined by counting immunoblots or densitometric scans; in all cases, the results were compatible with those of ELISA.

Several important conclusions were prompted by the data. (1) In the whole brain, the concentration of N-CAM gradually increased during the embryonic period, reached peak values

TARI.F. I

Concentration of $N$-CAM in different neural tissues during development

All data were results of triplicates in ELISA. For the whole brain, the average of three to four independent experiments (starting from different animals) was used; standard deviations were between 0.20 to 0.40 .

\begin{tabular}{lccccccc}
\hline \multirow{2}{*}{ Regions } & \multicolumn{5}{c}{ Nanograms of N-CAM/100 ng of Lysate Protein } \\
\cline { 2 - 8 } & $11 \mathrm{ED}^{a}$ & $14 \mathrm{ED}$ & $18 \mathrm{ED}$ & $1 \mathrm{D}^{b}$ & $7 \mathrm{D}$ & $21 \mathrm{D}$ & $180 \mathrm{D}$ \\
\hline Whole brain & 0.80 & 1.25 & 1.70 & 2.80 & 1.78 & 1.03 & 1.04 \\
Olfactory bulb & & & 1.80 & 3.21 & 3.00 & 3.64 & 3.65 \\
Cerebral cortex & & & & 1.55 & 1.25 & 1.28 & 0.89 \\
Hippocampus & & & & & 1.61 & 1.09 & 0.96 \\
Diencephalon & & & & 1.55 & 1.80 & 0.86 & 0.89 \\
Tectum & & & 1.74 & 2.48 & 3.21 & 0.77 & 0.67 \\
Cerebellum & & & 1.55 & 1.36 & 0.98 & 0.58 & 0.74 \\
Spinal cord & 0.80 & 1.13 & 1.47 & 2.11 & 1.32 & 0.54 & 0.54 \\
Trigeminal nerve & & & & & 1.55 & 0.33 & 0.44 \\
\hline
\end{tabular}

${ }^{a}$ ED, embryonic days as compared to figures in Theiler (1972).

${ }^{b} \mathrm{D}$, days after birth
(2.8 times adult level) around birth, and then declined until the third week postpartum. Thereafter, the concentration stayed constant into adult life (Table I, Fig. 2A). (2) A similar variation in N-CAM concentration was observed in most individual neural regions examined, but the times at which the peak concentrations of N-CAM appeared were different: cerebellum was earliest (peak at about 18 days of embryonic life), followed by the whole brain and spinal cord (peak at about 1 day of age), then the tectum and diencephalon (peak at about 7 days of age) (Table I, Fig. 2A). (3) A notable exception to this pattern was found for the olfactory bulb, in which the concentration of $\mathrm{N}$-CAM increased at birth and then remained at a high level ( $3 \%$ of the protein in the lysate) even in the adult (Table I, Fig. $2 A$ ). (4) The concentration of N-CAM in different neural tissues was similar during embryonic development (Fig. $2 A$, embryonic day 11,14 , and 18 ), but began to diverge at approximately the time of birth (Fig. $2 A$, Table I). In the adult, the olfactory bulb contained a relatively high concentration of $\mathrm{N}$ CAM $(3.6 \%)$, and the spinal cord and trigeminal nerve contained relatively low concentrations (about $0.5 \%$ ), whereas most other brain regions contained around $1 \%$ of the lysate protein as N-CAM (Table I).

In most of these studies, we analyzed the N-CAM present in total tissue lysates; however, several considerations suggested that most of this N-CAM was derived from the plasma membrane. In previous studies, N-CAM was found to be concentrated at the plasma membrane by immunofluorescence (Chuong et al., 1982) or immunoperoxidase staining methods (Rutishauser et al., 1978), and this pattern was unchanged
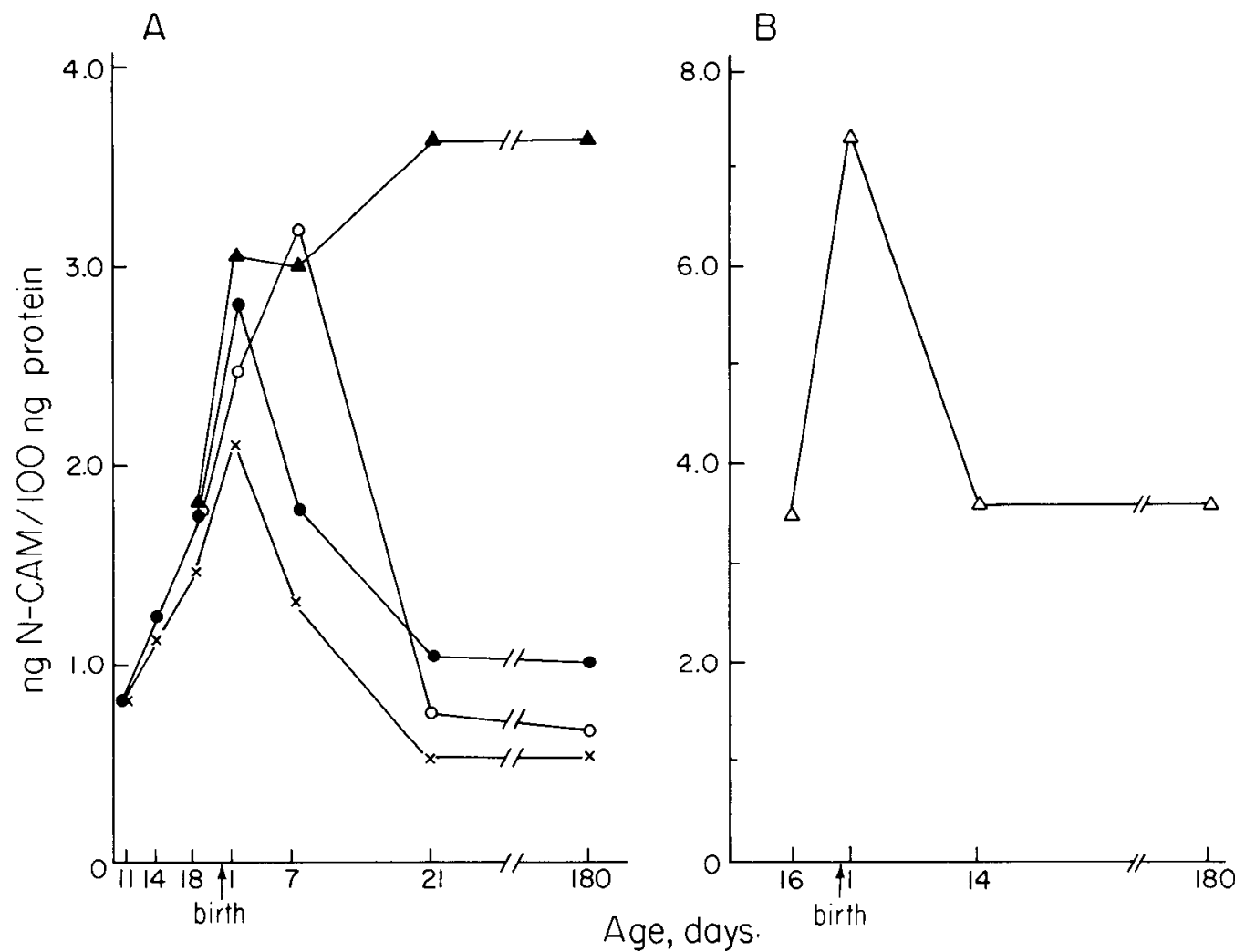

Figure 2. Temporal changes of the concentrations of N-CAM during development. A, Concentrations of N-CAM (from Table I) from lysates of whole brain (O) as well as from olfactory bulb $(A)$, tectum $(O)$, and spinal cord $(X)$ are plotted against developmental ages. Note that there is a peak in concentration of $\mathrm{N}$ $\mathrm{C} A \mathrm{M}$ around the time of birth in the whole brain, tectum, and spinal cord. The timing of this peak is different: it occurred in the spinal cord earlier than in the tectum, while the concentration of N-CAM in the olfactory bulb remained constantly high. $B$, Concentrations of N-CAM in membrane vesicles prepared from the whole brain were plotted against developmental ages. Note that the concentrations of N-CAM in membrane vesicles follow the same changing patterns as those in the total lysates shown in $A$. 
when the fixed cells were permeabilized prior to staining. In addition, preliminary subcellular fractionation studies indicated that most $(>86 \%)$ of the N-CAM was in the crude membrane fraction, and very little was found in the soluble fraction. When plasma membrane vesicles were further enriched on sucrose density gradients (as described under "Materials and Methods") and their N-CAM content was measured, the developmental pattern of the N-CAM concentration (nanograms of N-CAM per $100 \mathrm{ng}$ of membrane protein) was similar to that obtained with lysates (Fig. $2 B$ ). Although more detailed studies are needed to confirm the conclusion, the evidence accumulated so far suggests that the results derived from analysis of N-CAM in total lysates largely reflect changes in N-CAM on the plasma membrane.

These quantitative measurements of N-CAM included all forms of N-CAM recognized by the specific polyclonal rabbit anti-N-CAM antibody. Inasmuch as N-CAM exists in embryonic and adult forms, it was important to determine the prevalence of these different forms in each neural region, as well as to compare the time course of $\mathrm{E} \rightarrow \mathrm{A}$ conversion with the time course of the changes in N-CAM concentrations.

$E \rightarrow A$ conversion of $N$-CAM occurs at different rates in different neural regions. To obtain an average rate of $\mathrm{E} \rightarrow \mathrm{A}$ conversion, we first analyzed N-CAM from the whole brain at different developmental times by PAGE. This $\mathrm{E} \rightarrow \mathrm{A}$ conversion rate was then compared with rates determined in individual neural regions. An analysis of whole brain homogenates of various ages using rabbit anti-N-CAM antibodies is shown in Figure $3 \mathrm{~A}$. Before birth, N-CAM appeared as a broad $\mathrm{E}$ form band in PAGE; after birth, three bands of $M_{\mathrm{r}}=180,000,140,000$, and 120,000 , constituting the A forms of N-CAM, gradually emerged. These A forms of N-CAM persisted throughout adult life without undergoing further changes, even in "old" mice of
2 and 3 years of age. To determine quantitatively the different forms of N-CAM in the gel, the autoradiograph of Figure $3 A$ was scanned densitometrically. In this case, because changes in the ratios between the $\mathrm{E}$ form and the three $\mathrm{A}$ forms of N-CAM were of more concern than the absolute amounts, we normalized the area under each tracing to the same value to facilitate comparison. These normalized tracings showed that N-CAM from embryonic brains migrated as a broad peak around $M_{\mathrm{r}}=200,000$ constituting the E form. Around birth, three sharp peaks of $M_{\mathrm{r}}=180,000,140,000$, and 120,000 gradually emerged and increased in amount. By about 21 days of age, N-CAM consisted mainly of material distributed as three sharp peaks constituting the A forms (Fig. $3 B$ ). Thus, in the whole mouse brain, $\mathrm{E} \rightarrow \mathrm{A}$ conversion is a gradual process which starts around birth and is practically complete after 3 weeks.

To compare $\mathrm{E} \rightarrow \mathrm{A}$ conversion in different neural regions, mouse brains of different ages were dissected into separate parts, and the N-CAM in each region was examined by the immunoblot method. Exemplary analyses of cerebellum and tectum compared with whole brain are shown in Figure 4. Averaged over the whole brain, N-CAM was present mainly in the $\mathrm{E}$ form at 7 days after birth, largely in the A forms with some residual $\mathrm{E}$ form at 21 days, and completely in the $\mathrm{A}$ forms at 180 days. In contrast, in the cerebellum, the $\mathrm{A}$ forms had already appeared by 7 days and conversion was complete by 21 days. Very different results were obtained with tectum: N-CAM was present in the $\mathrm{E}$ form at 7 days, remained in the $\mathrm{E}$ form at 21 days, and did not appear as three $\mathrm{A}$ form bands until adulthood; even at 180 days, a small amount of $\mathrm{E}$ form persisted (Fig. 4).

Comparative densitometric scans of the autoradiographs shown in Figure 4 and of additional neural regions are shown in Figure 5. Differences in the $\mathrm{E} \rightarrow \mathrm{A}$ conversion between various
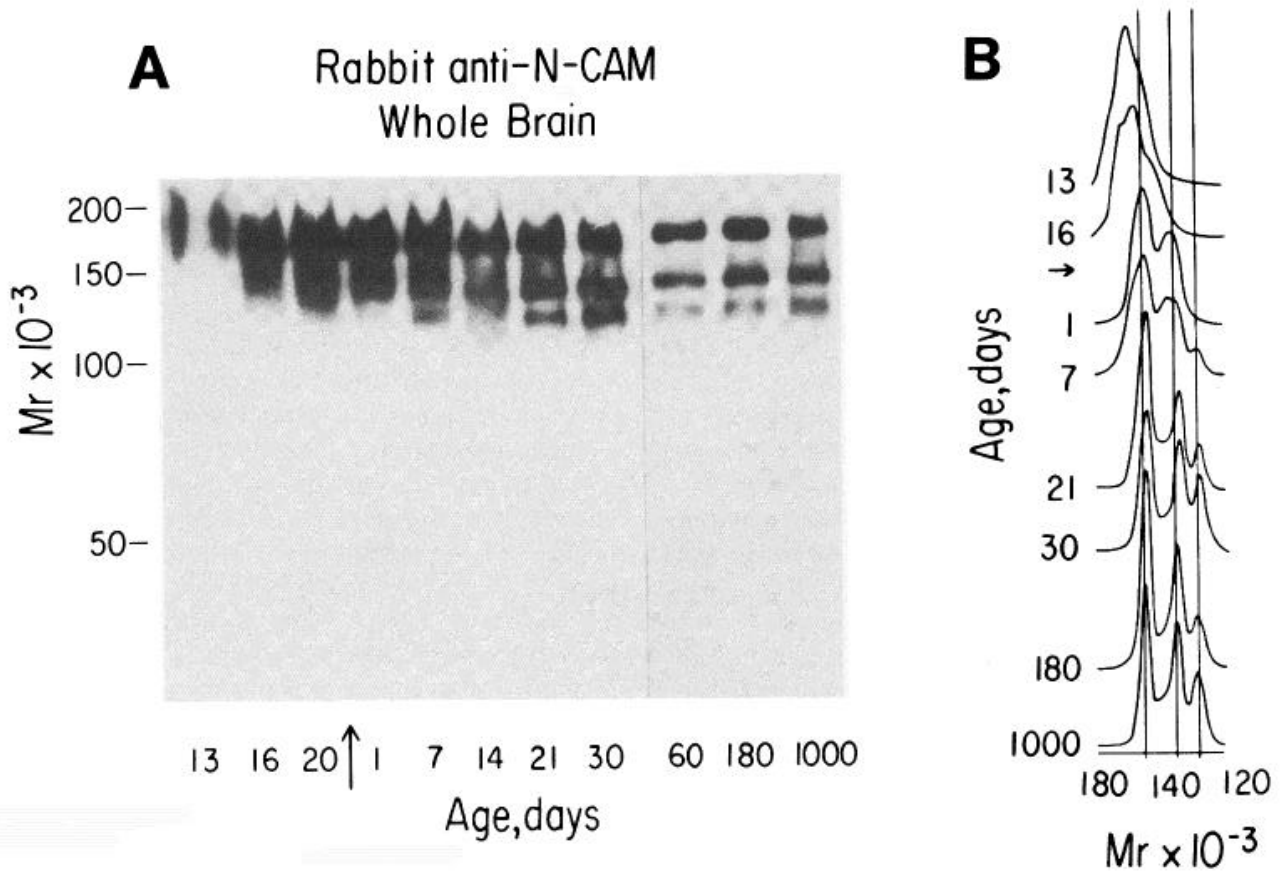

Figure 3. Analysis of the forms of N-CAM from whole mouse brains of different ages. A, Brain lysates were first resolved by $7.5 \%$ PAGE, transferred to nitrocellulose paper, and reacted with rabbit anti-N-CAM antibodies. Bound antibodies were detected by $\left[{ }^{125} \mathrm{I}\right]$ protein $\mathrm{A}$ binding and visualized by autoradiography. The ages of mice examined are shown in embryonic days; then, following the arrow, in days after birth. $B$, Densitometric scans of each lane of the autoradiograph in $A$. The abscissa is relative molecular weight; the three A forms of $M_{r}=180,000,140,000$, and 120,000 are marked. The ordinate is optical density, representing the relative amount of N-CAM. The arrow at the left margin denotes birth; above it, ages are shown as embryonic days, below it, as postnatal days. For purposes of comparison, the total areas under the tracings were normalized to the same value. 


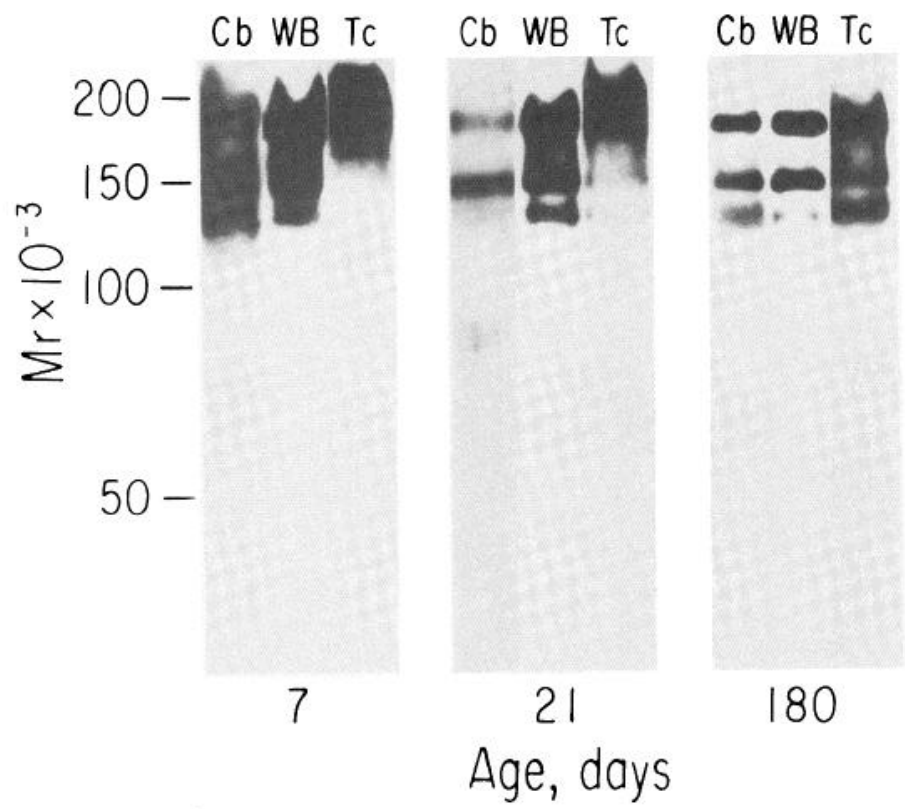

Figure 4. Gel patterns revealing maturation of N-CAM in cerebellum $(C b)$, whole brain $(W B)$, and tectum $(T c)$ shown at three different ages. Extracts were prepared as described for Figure $3 A$ and reacted with rabbit anti-N-CAM antibodies. Ages were expressed as days after birth. Note that the relative $\mathrm{E} \rightarrow \mathrm{A}$ conversion rates among these three regions are: cerebellum $>$ whole brain $>$ tectum.

regions are best seen by comparing the tracings of N-CAM from 21-day-old animals. The tracings are arranged in decreasing order of their apparent rates of conversion: N-CAM in the whole brain at this age consisted largely of the three A form bands; although the cerebral cortex had a similar pattern, $\mathrm{N}$-CAMs from retina, cerebellum, and spinal cord were more completely converted to the $\mathrm{A}$ forms by 21 days. In contrast, hippocampus, olfactory bulb, diencephalon, and tectum each still contained larger amounts of the E form of N-CAM at 21 days. In the adult (180 days), the N-CAMs present in most regions appeared as three peaks representing $\mathrm{A}$ forms, except in the diencephalon and tectum which still retained some of the $\mathrm{E}$ form, as evidenced by the asymmetry of the large $M_{\mathrm{r}}=$ 180,000 peak. Quantitative measurements made by Gaussian curve simulations of the three major A form peaks (Edelman and Chuong, 1982) clearly revealed the presence of different amounts of the A forms (Table II). It should be noted that only in the retina does the conversion appear complete by this criterion.

Of all the tissues examined, $\mathrm{E} \rightarrow \mathrm{A}$ conversion was most rapid in dorsal root ganglia. In the 15-day embryonic dorsal root ganglia, N-CAM existed largely in the $\mathrm{E}$ form with small amounts of $\mathrm{A}$ forms. It was striking to observe that at 1 day after birth, when all other brain regions still expressed the $\mathrm{E}$ form of N-CAM (for an example, see the whole brain in Fig. 3 ), the N-CAM in dorsal root ganglia already consisted almost entirely of the A forms (see also the comparison with spinal cord described later in Fig. $8 B$ ).

In addition to mouse brains, rat and chicken brains were also examined for the rates of $\mathrm{E} \rightarrow \mathrm{A}$ conversion in different regions. In the rat, the relative rates and time courses were very similar to those found in the mouse. Relative differences in $\mathrm{E} \rightarrow \mathrm{A}$ conversion rates were also observed in the chicken: spinal cord and retina (mostly converted around the 15 th embryonic day) were faster than forebrain (converted around the first week after birth), which in turn preceded tectum (still largely $\mathrm{E}$ form at 2 weeks after birth). All of these observations indicate that, in the several species studied, $\mathrm{E} \rightarrow \mathrm{A}$ conversion does not occur at a uniform rate throughout different defined regions of the nervous system.

Differences in $E \rightarrow A$ conversion rates are also detected by a monoclonal antibody specific for the $E$ form of $N$-CAM. MAb $15 \mathrm{G} 8$ reacts with embryonic N-CAM but not with neuraminidase-treated N-CAM (Chuong et al., 1982), suggesting that sialic acid may be part of or may affect the antigenic determinant recognized by this antibody. Because the $\mathrm{E}$ form of $\mathrm{N}$-CAM contains 3 times as much sialic acid as N-CAM isolated from adult brains (Rothbard et al., 1982), it was of particular interest to compare the binding of MAb 15G8 to embryonic and adult N-CAM. When MAb 15G8 was reacted with whole brain homogenates (Fig. 6A), it bound to the embryonic form of $\mathrm{N}$-CAM. When extracts from progressively older mice were used, binding of MAb 15G8 gradually decreased and no binding was observed to the N-CAM from adult brains. The loss of MAb 15G8 binding closely paralleled the previously observed change in the forms of N-CAM (Fig. 3; Edelman and Chuong, 1982). Taken together, these experiments imply that the binding of MAb $15 \mathrm{G} 8$ requires the presence of a sialic acid containing moiety specific to the $\mathrm{E}$ form of N-CAM. This result also suggests that the decrease in binding of MAb $15 \mathrm{G} 8$ can serve as an independent criterion to assess the rate of $\mathrm{E} \rightarrow \mathrm{A}$ conversion.

When MAb $15 \mathrm{G} 8$ was reacted with extracts from separate brain regions, N-CAM in certain regions of the adult brain, such as the diencephalon, bound a small amount of MAb 15G8 (Fig. 6A). The densitometric scan of the autoradiograph shown in Figure $6 B$ clearly illustrates the gradual decrease in binding of MAb $15 \mathrm{G} 8$ to N-CAM obtained from the whole brain, as well as the persistent MAb 15G8 binding to N-CAM from diencephalon. This result also supports the notion that the asymmetric $M_{\mathrm{r}}=180,000$ peak found in the adult diencephalon (Fig. 5) reflects the presence of the E form of N-CAM at the high molecular weight side of the peak.

Comparison of data in Tables II and III indicates that not all of the embryonic N-CAM is reactive with MAb 15G8. The fraction of total N-CAM to which MAb $15 \mathrm{G} 8$ can bind was highest in the near-term embryonic brains (about 50\%, determined either by counting the gel blot as described in the legend to Table III or by immunoprecipitation as described in Edelman and Chuong, 1982) but decreased when the brain matured. As expected, this decrease also occurred at different rates in different brain regions (Table III). In most brain regions, binding was lost during the first month after birth; however, in diencephalon, tectum, and olfactory bulb, a small but significant amount of MAb $15 \mathrm{G} 8$ binding persisted even in the adult mouse.

In assessing all of the comparisons made so far, a technical point is worthy of mention. When the lysates from the whole brain were analyzed, the results represented averages over large cellular populations of different composition and size. Because we used the same amount of lysate proteins for each analysis, the results obtained from the whole brain were more similar to those of the larger cellular populations, such as cerebral cortex. When a small brain area such as the tectum was analyzed, the result reflected the particular composition of that smaller cellular population. It is therefore not surprising that the amount of $\mathrm{E}$-form N-CAM present in a smaller region like the diencephalon was not detected when preparations from the whole brain were used.

The results obtained by the two independent criteria described above demonstrate unequivocally that there are differences in the relative rates of $\mathrm{E} \rightarrow \mathrm{A}$ conversion in different brain regions. To facilitate comparison, a "conversion index" in which the two criteria were equally weighted was devised to summarize all of the results (Table IV). The existence of these differences prompted us to search for salient differences in particular 


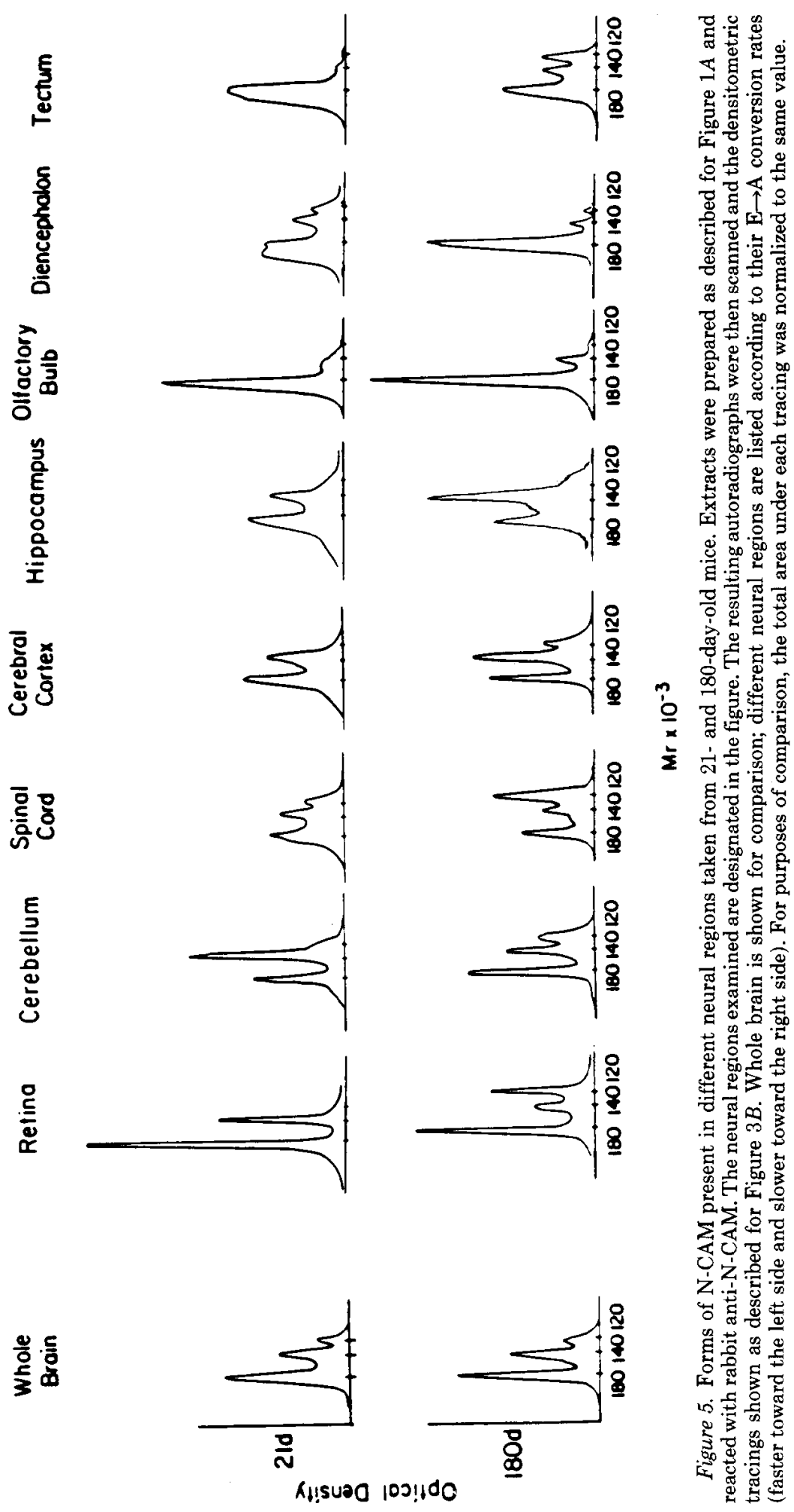


pathways, for cephalocaudal conversion gradients within regions, and for possible qualitative alterations of N-CAM in different regions. We first turned our attention to regions where specific mapping patterns were well established, such as the retinotectal projection.

$E \rightarrow A$ conversion of $N-C A M$ in the retina of the mouse and chick is much faster than in the optic tectum. Mouse tectum, which includes the superior and inferior colliculi, expressed a relatively large amount of the $\mathrm{E}$ form of N-CAM at 21 days of age (see Tables II and III); in contrast, N-CAM in the mouse retina converted at a much faster rate (Tables II and III) and already expressed the A forms of N-CAM at 14 days after birth. In order to compare the relative $\mathrm{E} \rightarrow \mathrm{A}$ conversion rates of retina and optic tectum in detail, we turned to the chicken for practical reasons dictated by tissue size. Lysates of retinas and optic tecta from 6-day (Hamburger and Hamilton stage 29), 10-day

\section{TABLE II}

Quantitative comparison of the relative amounts of the A forms of $\mathrm{N}$-CAM in different brain regions of 21- and 180-day-old mice

\begin{tabular}{lcc}
\hline \multirow{2}{*}{ Brain Regions } & \multicolumn{2}{c}{ Area of Total A Form Peaks } \\
\cline { 2 - 3 } & 21 days & 180 days \\
\hline & & \\
Retina & 95 & 95 \\
Cerebellum & 73 & 77 \\
Spinal cord & 71 & 75 \\
Whole brain & 64 & 75 \\
Cerebral cortex & 50 & 73 \\
Hippocampus & 50 & 57 \\
Olfactory bulb & 48 & 66 \\
Diencephalon & 44 & 54 \\
Tectum & 35 & 65 \\
\hline
\end{tabular}

${ }^{a}$ The amounts of the A form peaks were calculated by analyzing the densitometric tracings (Fig. 5) as described previously (Edelman and Chuong, 1982). The sum of areas under the three simulated $A$ form peaks was divided by the total area and shown as percentage values. (stage 36), and 15-day (stage 41) chick embryos and from 7day-old newborn chickens were reacted with rabbit antichicken $\mathrm{N}-\mathrm{CAM}$ and MAb 15G8. In the retina, the $\mathrm{E}$ form of $\mathrm{N}-\mathrm{CAM}$ was steadily converted to the A forms of N-CAM during the period between 6 embryonic days (39\% A forms, using the Gaussian curve simulation) and 7 days after birth (61\% A forms) (Fig. 7). Comparable results were obtained in the mouse optic tectum: the E form of N-CAM was present throughout embryonic development and up to 7 days after birth, when some A forms (33\%) started to appear and coexisted with the E form of N-CAM (Fig. 5).

In the chick, similar results were also obtained using MAb $15 \mathrm{G} 8$. The fraction of N-CAM that reacted with MAb $15 \mathrm{G} 8$ in

\section{TABLE III}

Comparison of the amounts of the E form of N-CAM as judged by reactivity with $M A b 15 G 8$

$\mathrm{N}$-CAM which reacts with MAb $15 \mathrm{G} 8$ is shown as percentage of $\mathrm{N}$ CAM which reacts with rabbit anti-N-CAM. The amount of N-CAM that reacted with MAb $15 \mathrm{G} 8$ was measured by counting the gel blot pieces in a gamma counter and comparing the values to the N-CAM standard curve using the method described under "Materials and Methods." This value was then divided by the corresponding total $\mathrm{N}$ CAM value in Table I to obtain percentages.

\begin{tabular}{lcc}
\hline \multirow{2}{*}{ Brain Regions } & \multicolumn{2}{c}{$\begin{array}{c}\text { Percentage of N-CAM that Binds } \\
\text { MAb 15G8 }\end{array}$} \\
\cline { 2 - 3 } & 21 Days & 180 Days \\
\hline Retina & $<2$ & $<2$ \\
Spinal cord & $<2$ & $<2$ \\
Cerebellum & 2 & $<2$ \\
Cerebral cortex & 3 & $<2$ \\
Whole brain & 17 & $<2$ \\
Hippocampus & 21 & $<2$ \\
Olfactory bulb & 13 & 6 \\
Diencephalon & 39 & 6 \\
Tectum & 43 & 5 \\
\hline
\end{tabular}

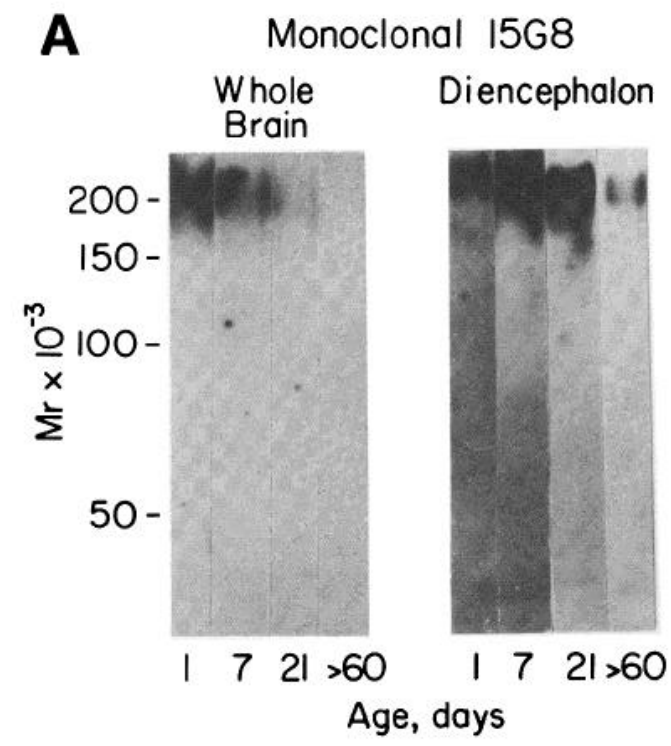

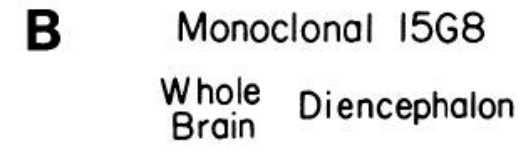

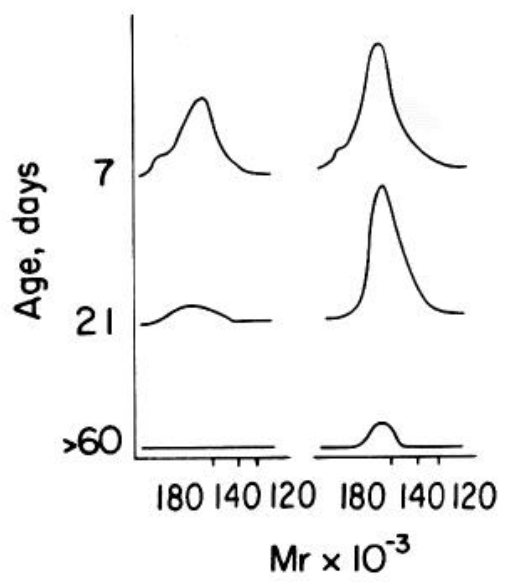

Figure 6. Differences in binding of MAb 15G8 to N-CAMs from the whole brain and diencephalon. $A$, The samples were prepared as described for Figure $1 A$, except the antibody used was MAb $15 \mathrm{G} 8$. The binding of the monoclonal antibody was amplified by rabbit anti-mouse immunoglobulin before reacting with $\left[{ }^{125} \mathrm{I}\right]$ protein $\mathrm{A}$. The ages of the mice exmained are shown below as days after birth. Note that MAb 15G8 recognized only the broad diffuse $\mathrm{E}$ form of N-CAM, but not the A forms of NCAM in the 21- and 60-day samples (cf. Fig. $3 A$ for whole brain). $B$, Densitometric scans of the autoradiograph in $A$. The ordinate is optical density, and the total areas under the tracings reflect the relative amounts of MAb $15 \mathrm{G} 8$ binding. 
TABLE IV

Relative rates of $E \rightarrow A$ conversion in different brain regions

To compare the relative $\mathrm{E} \rightarrow \mathrm{A}$ conversion rate that was judged by the two independent criteria in this study, a conversion index $(C)$ was devised.

$$
C=\left[\left(A / A_{\max }\right)+\left(1-B / B_{\max }\right)\right] / 2
$$

$C$ is the conversion index, reflecting the completeness of $\mathrm{E} \rightarrow \mathrm{A}$ conversion at a particular age. $A$ is the proportion of total $A$ form peaks expressed in percentage (from Table II), $A_{\max }$ is the maximum of $A$ ever obtained, which is $95 \%$. $B$ is the percentage of N-CAM which binds MAb 15G8 (from Table III), $B_{\max }$ is the maximum of $B$ ever obtained, which is $50 \%$. The average conversion index shown here is the average of the values of the conversion indices from 21 days and 180 days of age and is expressed as a percentage.

\begin{tabular}{clc}
\hline \multirow{2}{*}{ Rate } & \multicolumn{1}{c}{ Brain Region } & $\begin{array}{c}\text { Average Conversion } \\
\text { Index }\end{array}$ \\
\cline { 2 - 3 } Fast (before 21 days) & $\begin{array}{c}\text { Dorsal root ganglia } \\
\text { Retina }\end{array}$ & 100 \\
& Cerebellum & 100 \\
& Spinal cord & 89 \\
& Cerebral cortex & 89 \\
& Whole brain & 82 \\
& Olfactory bulb & 79 \\
& Hippocampus & 71 \\
& Diencephalon & 68 \\
Slow (after 30 days) & Tectum & 53 \\
& & 52 \\
\hline
\end{tabular}

retina lysates decreased by $62 \%$ from 10 embryonic days to 7 days after birth. In tectum, this fraction decreased by only $9 \%$ during the corresponding period. Therefore, both of our criteria indicated that $\mathrm{E} \rightarrow \mathrm{A}$ conversion of $\mathrm{N}$-CAM in chick retina occurred much more rapidly than in the optic tectum.

To determine whether there is a gradient in the rates of $\mathrm{E} \rightarrow \mathrm{A}$ conversion within the retinas or tecta, we dissected 9 day and 15-day chicken embryo retinas into anterior, posterior, dorsal, and ventral portions and examined the forms of $\mathrm{N}$ $\mathrm{CAM}$ in each region. No differences among the regions were detected either by the rabbit anti-N-CAM antibody or by MAb 15G8 using the methods described above. Tecta from 10-day and 15-day chicken embryos and 7-day-old newborn chickens were also dissected into five approximately equal portions either along the anterior-posterior axis or the medial-lateral axis of tectum. Again, no apparent difference in $\mathrm{E} \rightarrow \mathrm{A}$ conversion rates of N-CAM were detected. However, for both retinas and tecta, we cannot exclude the possibility that some difference might exist at finer levels of resolution or along different axes. The anatomy of the spinal cord and the chains of dorsal root ganglia provided a good opportunity to look for other possible gradients of $\mathrm{E} \rightarrow \mathrm{A}$ conversion within particular neural regions.

Mulurulion gradients of N-CAM are detectable in mouse spinal cord and in chains of dorsal root ganglia. Spinal cords from 15-day embryos and from 1-, 10-, and 15-day-old mice were dissected into cervical (C2,C3), thoracic (T9,T10), and lumbar regions (L4,L5), and the forms of N-CAMs at each level were examined. In 15-day embryonic spinal cords, N-CAM was present as a broad diffuse peak with no apparent differences between the cervical, thoracic, and lumbar cords. One day after birth, in the cervical cord, the $M_{r}=180,000$ peak began to emerge out of the broad peak (Fig. $8 A$ ) and the total A form area was $34 \%$ (Table $\mathrm{V}$ ); both the thoracic and lumbar cords still contained broad $\mathrm{E}$ form peaks ( $28 \% \mathrm{~A}$ forms), and the binding of MAb $15 \mathrm{G} 8$ was 1.6 times that of the cervical cord. At 10 days after birth, in the cervical cord, the A form peaks were higher ( $53 \% \mathrm{~A}$ forms); in the thoracic cord, the $M_{\mathrm{r}}=$ 180,000 peak had just started to emerge; and in the lumbar cord, N-CAM still remained mainly in the $\mathrm{E}$ form (Fig. $8 A$, Table V). At 15 days of age, the $\mathrm{E} \rightarrow \mathrm{A}$ conversion was nearly complete in the cervical cord and was partially complete in the thoracic cord (Fig. 8A, Table V); in the lumbar cord, the A form peaks were just appearing, and binding of MAb $15 \mathrm{G} 8$ was 2 times that of the cervical cord.

Dorsal root ganglia from cervical (C2,C3), thoracic (T9,T10), and lumbar $(\mathrm{L} 4, \mathrm{~L} 5)$ regions were also examined. In 15-day mouse embryos, the $\mathrm{N}$-CAMs in all three regions were largely in the $\mathrm{E}$ form, with no apparent differences between regions. In 1-day-old mice, the N-CAM in cervical and thoracic ganglia had already converted into the $\mathrm{A}$ forms (Fig. $8 B$, Table V), but the lumbar ganglia still retained some broad $E$ form peak together with the three $\mathrm{A}$ form peaks (Fig. $8 B$, Table V). In the adult, dorsal root ganglia from all three regions expressed the three A forms of N-CAM. Therefore, there is a cephalocaudal maturation gradient of N-CAM in both dorsal root ganglia and the spinal cord; this gradient was definite but not steep.

These observations prompted us to look for other differences in the conversion rate of N-CAM within the same neural regions. $\mathrm{N}$-CAMs from the left and right cerebral cortex of 5-, 10 -, and 15-day-old mice were compared, but no significant differences were observed in their $\mathrm{E} \rightarrow \mathrm{A}$ conversion rates. Another comparison was suggested by possible effects reflecting phylogenetic considerations. Cerebellum (21 days) was dis-

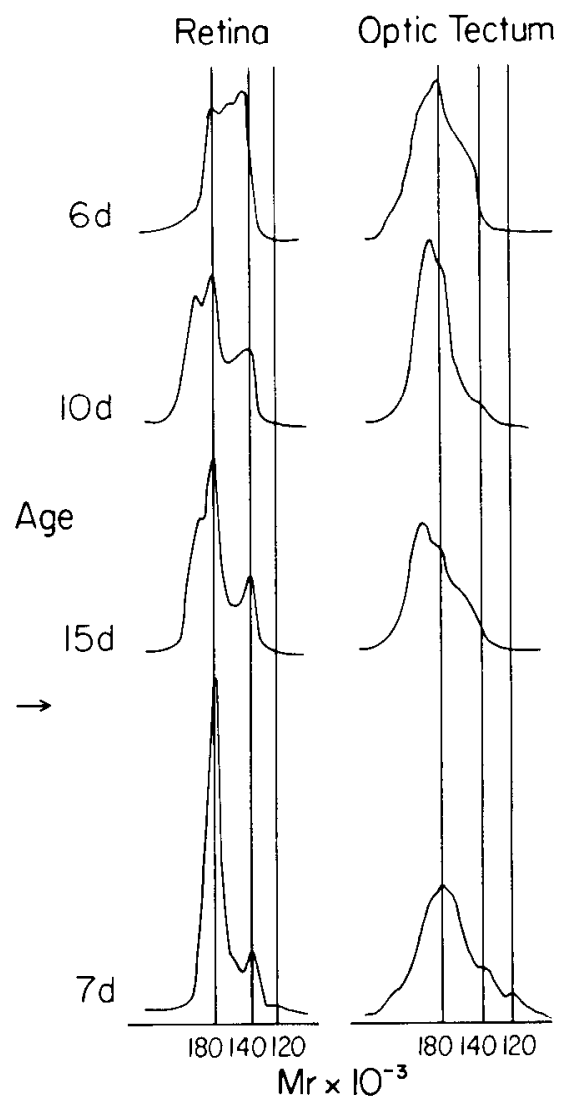

Figure 7. Differences in the $\mathrm{E} \rightarrow \mathrm{A}$ conversion rates of $\mathrm{N}$-CAM in the chicken retina and optic tectum. Tissue lysates were prepared as described in the legend to Figure 3 and reacted with rabbit anti-chicken $\mathrm{N}$-CAM. The arrow at the left margin denotes birth; age is shown as days. Note that the $\mathrm{E} \rightarrow \mathrm{A}$ conversion in retina (left) is much faster than in optic tectum (right). For purposes of comparison, the areas under the tracings were normalized to the same value. 
A.

$$
\text { Spinal Cord }
$$

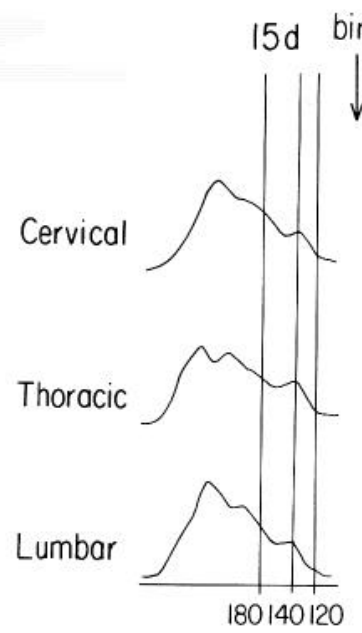

Id

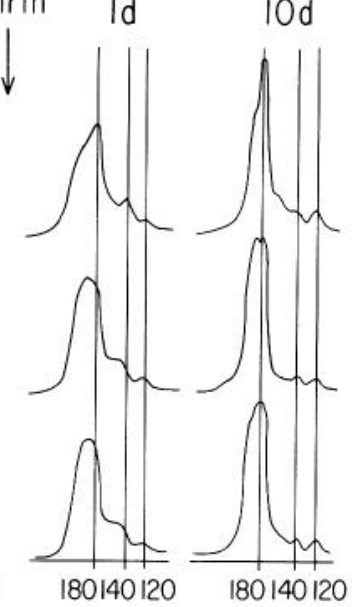

$\mathrm{Mr} \times 10^{-3}$
B. Dorsal Root Ganglia

$15 d$

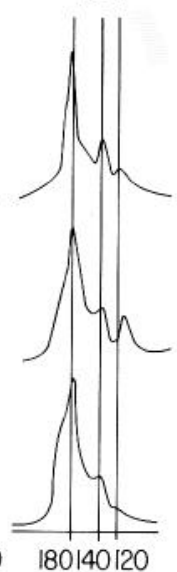

180140120

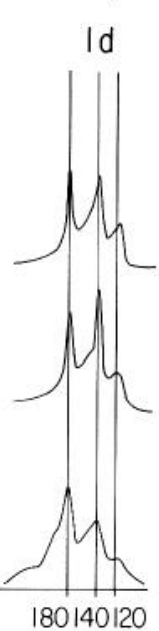

$\mathrm{Mr} \times 10^{-3}$

Figure 8. Cephalocaudal maturation gradient of N-CAM in the spinal cord and dorsal root ganglia. Tissue lysates were prepared as described in the legend to Figure 3 and reacted with rabbit anti-mouse-N-CAM. Age is shown in days. A, Spinal cord. At embryonic day 15, $\mathrm{N}$-CAM patterns in cervical, thoracic, and lumbar regions are similar; at 1 day after birth, $\mathrm{N}$-CAM in the cervical region starts to convert to the A forms but remains the same in the thoracic and lumbar region. At 10 days of age, N-CAMs in the cervical cord have converted toward the A forms; N-CAM in the thoracic cord has started to convert, but the lumbar cord retains mainly the $\mathrm{E}$ form. At 15 days of age, $\mathrm{N}$-CAMs at all three levels are in the middle of $\mathrm{E} \rightarrow \mathrm{A}$ conversion, but the order is still cervical $>$ thoracic $>$ lumbar. $B$, Dorsal root ganglia. At 1 day after birth, N-CAMs in the cervical and thoracic level of ganglia have already largely converted to the A forms. In the lumbar ganglia, N-CAM remains in the E form, as indicated by the broad peaks to the left of the $M_{\mathrm{r}}=180,000$ peak and in between the two A form peaks of $M_{\mathrm{r}}=180,000$ and 140,000. In both spinal cord and dorsal root ganglia, the relative conversion rates of $\mathrm{N}-\mathrm{CAM}$ are cervical $>$ thoracic $>$ lumbar.

TABLE V

Comparison of the amounts of the A forms of N-CAM in cervical, thoracic and lumbar spinal cords and dorsal root ganglia

\begin{tabular}{lcccc}
\hline \multirow{2}{*}{ Region } & \multicolumn{3}{c}{ Areas of Total A Form Peaks ${ }^{a}$} \\
\cline { 2 - 4 } & \multicolumn{3}{c}{ Spinal Cord } & $\begin{array}{c}\text { Dorsal Root } \\
\text { Ganglia } \\
\text { (1 Day) }\end{array}$ \\
\cline { 2 - 4 } & 1 Day & 10 Days & 15 Days & $\%$ \\
Cervical & 34 & 53 & 64 & 74 \\
Thoracic & 28 & 42 & 50 & 71 \\
Lumbar & 28 & 39 & 47 & 56 \\
\hline
\end{tabular}

${ }^{a}$ The amounts of the A form peaks were analyzed from the tracings in Figure 8 using Gaussian curve simulation (Edelman and Chuong, 1982).

sected into flocculus (archicerebellum), culmen (paleocerebellum), and the remaining neocerebellum. All three areas contained the A forms of N-CAM without apparent difference.

Differences in antigenic determinants of $N$-CAMs from different tissues are detected by two independent monoclonal antibodies. A survey of several monoclonal antibodies revealed that MAb $9 \mathrm{E} 11$ bound only to N-CAMs present in some adult neural tissues. Rabbit anti-N-CAM recognized N-CAMs present in all neural regions examined, including the olfactory mucosa, pyriform cortex, parietal cortex, cerebellum, and spinal cord (Fig. 9). In contrast, MAb 9E11 failed to recognize N-CAMs present in the olfactory mucosa and adult cerebellum but did precipitate $\mathrm{N}$-CAMs from pyriform, parietal cortex, and, to a lesser extent,

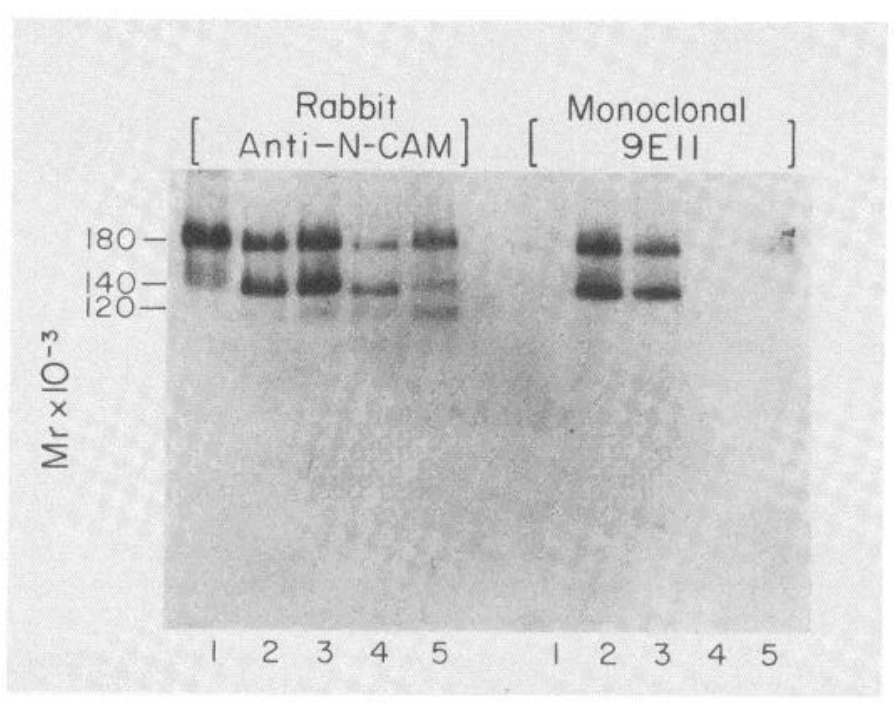

Figure 9. Comparative reactivities of N-CAMs from different adult neural tissues with rabbit anti-N-CAM and with MAb 9E11. The figure shows an autoradiograph of immunoprecipitates from iodinated membrane vesicle extracts. This experiment was done by immunoprecipitation inasmuch as MAb 9E11 does not react with N-CAM on the nitrocellulose blot. The neural tissues examined are: lanes 1 , olfactory mucosa; lanes 2, pyriform cortex; lanes 3, parietal cortex; lanes 4, cerebellum; lanes 5 , spinal cord. Note that while rabbit anti-N-CAM reacted with N-CAMs from all five regions, MAb $9 \mathrm{E} 11$ failed to react with N-CAMs from olfactory mucosa and cerebellum. 
spinal cord (Fig. 9) and olfactory bulb (not shown). This variation is particularly intriguing, because MAb $9 \mathrm{E} 11$ did bind to the E form of N-CAM from embryonic cerebellum. It should be noted that, although the antigenic determinant that binds MAb 9E11 has not yet been defined, it differs from that recognized by MAb $15 \mathrm{G} 8$ in that it does not involve the sialic acid moiety.

We have shown previously that in mouse cerebellum, the loss of MAb $9 \mathrm{E} 11$ binding occurred during the first 3 weeks after birth (Edelman and Chuong, 1982). The present results therefore indicate that, in addition to the loss of sialic acid, the $\mathrm{E} \rightarrow$ A conversion process in cerebellum is accompanied by the loss of the antigenic determinant recognized by MAb 9E11. The absence of this determinant in adult cerebellum is unlikely to be the result of degradation during sample preparation because control experiments had been carried out, in which ${ }^{125}$ I-labeled extract from the parietal cortex was incubated with unlabeled cerebellar extract, and ${ }^{125}$ I-labeled cerebellar extract was incubated with unlabeled parietal cortex extract, before processing for immunoprecipitation. These mixing experiments did not lead to any change in the differential binding characteristics of the $\left.{ }^{125} \mathrm{I}\right] \mathrm{N}-\mathrm{CAM}$ with MAb 9E11.

Another difference in the antigenic determinants of N-CAM from different sources was recognized by monoclonal anti-(NCAM) No. 5. MAb No. 5 binds to N-CAM purified from brains; but when embryonic muscle was tested, the muscle N-CAM that was immunoprecipitated by rabbit anti-N-CAM or MAb $15 \mathrm{G} 8$ was not recognized by MAb No. 5 . These studies lead to the conclusion that there are subtle differences in the conformation or antigenic determinants of N-CAMs from different neural regions. Although the basis for these differences remains to be determined, we were impelled by these results to look for further local differences in N-CAM expression.

The ratios of the three $A$ form peahs are different in some neural tissues. Another significant variation in N-CAM expression found was a difference in the ratios between the three $A$ forms in certain neural tissues. As shown in the gel scan of N-CAM from the whole brain (Fig. 10), the bands corresponding to the three $\mathrm{A}$ forms are present at an average intensity ratio of $51: 33: 17$. In contrast, the $M_{\mathrm{r}}=180,000$ component was dominant in N-CAM from adult olfactory mucosa and olfactory bulb (Fig. 10), whereas the $M_{\mathrm{r}}=120,000$ component was more apparent in N-CAM from spinal cord (Fig. 10) and brainstem (not shown). Comparison of N-CAMs from the olfactory mucosa and olfactory bulb of the rat revealed that the $M_{r}=180,000$ components were also dominant. Moreover, characteristic A forms of N-CAM were also detected in the following neural or neurally related tissues of adult mice: pituitary gland (dominant $M_{\mathrm{r}}=140,000$ component), trigeminal nerve (all three $\mathrm{A}$ forms, but relatively more of the $M_{\mathrm{r}}=140,000$ and 120,000 components), and adrenal gland (all three A forms).

Although the possibility that the lower molecular weight A form bands are proteolytic fragments of higher molecular weight bands cannot be rigorously excluded, this appeared unlikely because similar patterns were obtained when tissues were homogenized immediately in boiling $1 \%$ SDS buffer. Moreover, when the lysates from olfactory bulb (which contained mainly the $M_{\mathrm{r}}=180,000$ component) and spinal cord (which contained mainly the $M_{\mathrm{r}}=120,000$ component) were mixed in different proportions during sample preparation, the results (Fig. 11, solid lines) were very similar to the expected values mathematically derived (Fig. 11, dashed lines). This suggests that the spinal cord extracts had no effect in converting the $M_{\mathrm{r}}=180,000$ form into the $M_{\mathrm{r}}=120,000$ form during sample preparation. It seems likely that the observed differences in N-CAM represent true physiological modifications of $\mathrm{N}$-CAM expression in different neural regions, possibly reflective of different cellular populations or of variant schedules of differentiation.

\section{Discussion}

Although previous work has demonstrated that N-CAM is present in different forms in embryonic and adult brains of chickens (Rothbard et al., 1982) and mice (Edelman and Chuong, 1982), many basic parameters of the developmental regulation of N-CAM remained to be determined. In particular, the functional significance of $\mathrm{E} \rightarrow \mathrm{A}$ conversion in vivo remained to be explored. To clarify these issues, we conducted the present

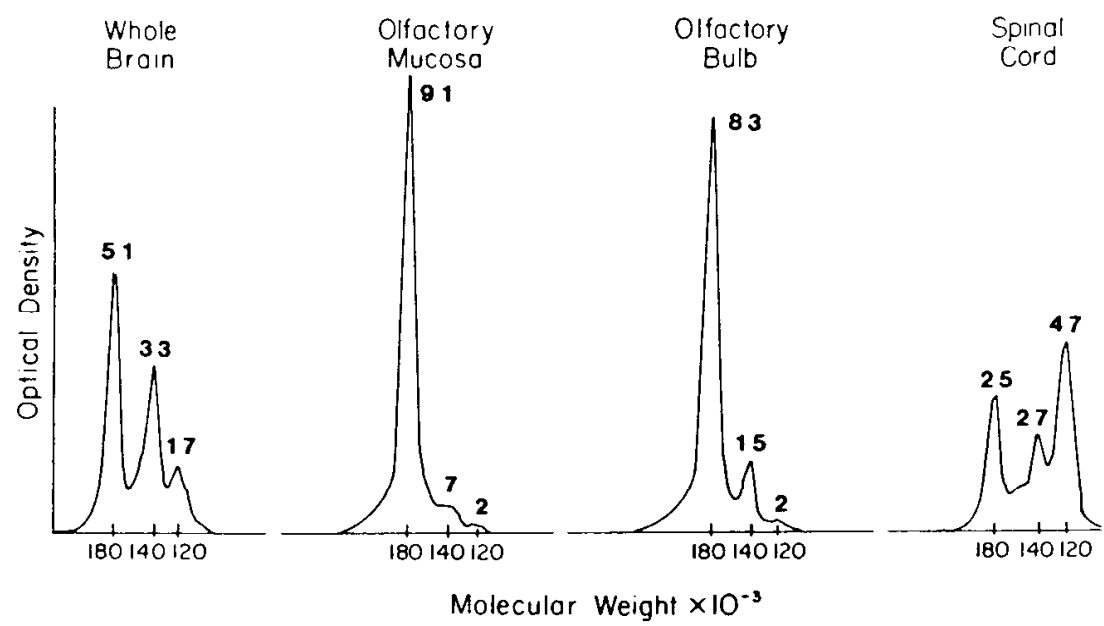

Figure 10. The relative proportions of the three A forms (components of $M_{\mathrm{r}}=$ $180,000,140,000$ and 120,000) in different neural regions of adult mouse. Extracts from the whole adult brain, olfactory mucosa, olfactory bulb, and spinal cord were prepared as described for Figure 3A and reacted with rabbit anti-N-CAM. The resultant autoradiograph was scanned and the densitometric tracings were prepared as described for Figure $3 B$. For purposes of comparison, the areas under each tracing were normalized to the same value. The three A form peaks were simulated with Gaussian curves (Edelman and Chuong, 1982), and the ratios of the three areas under each of the simulated curves are shown near the tip of each peak. Note that N-CAMs in the whole brain have an average pattern shared by most other neural regions. While N-CAMs in the olfactory mucosa and bulb have a dominant $M_{\mathrm{r}}=180,000$ peak, at the other extreme, N-CAMs in the spinal cord have a dominant $M_{\mathrm{r}}=120,000$ peak. 


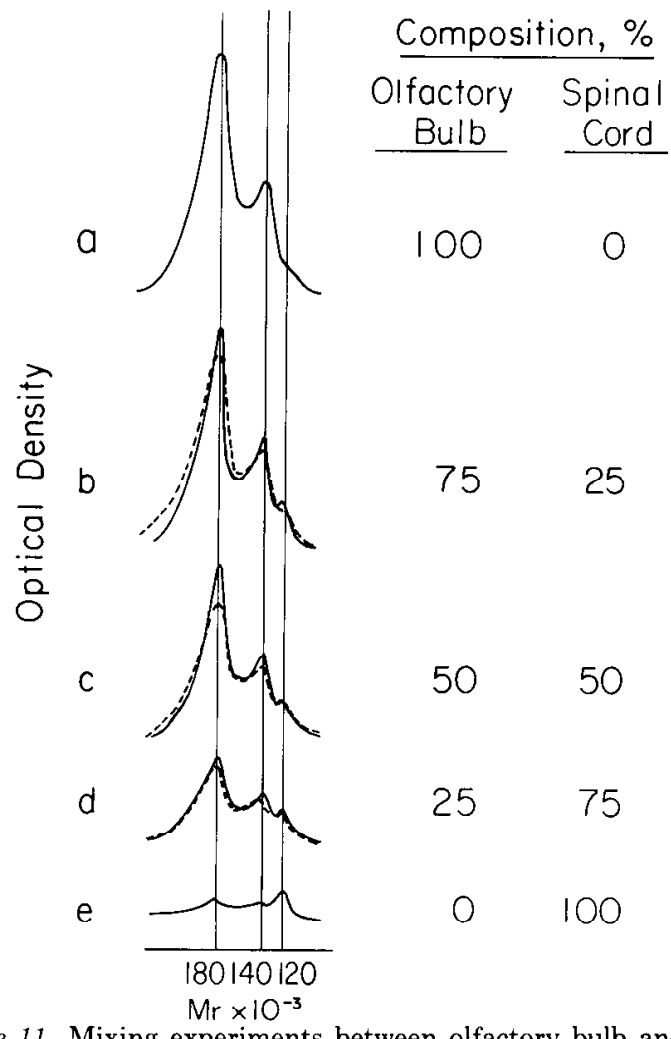

Figure 11. Mixing experiments between olfactory bulb and spinal cord lysates. One hundred-microgram lysate proteins from adult olfactory bulb $(a)$ and spinal cord $(e)$ were processed as described in the legend to Figure 3, except the area under each tracing was not normalized. The olfactory and spinal cord lysates were then mixed at ratios of 75:25, 50:50, and $25: 75$ (Solid lines in $b, c$, and $d$, respectively), and incubated for $1 \mathrm{hr}$ on ice. On the other hand, tracing $a$ and tracing $e$ were added up mathematically as $3 / 4 a+1 / 4 e$ (dashed line in $b$ ), $2 / 4 a+$ $2 / 4 e$ (dashed line in $c$ ), and $1 / 4 a+3 / 4 e$ (dashed line in $d$ ). The solid lines and the dashed lines are very similar in $b, c$, and $d$, indicating that no artifactual interconversion occurred during sample processing.

study to determine the time course of $\mathrm{E} \rightarrow \mathrm{A}$ conversion as well as to test for quantitative and qualitative changes in N-CAM in different neural regions during development.

The major findings may be summarized as follows. (1) In all brain regions examined, the concentration of N-CAM changed during development: it gradually increased during the embryonic period, reached a peak in the perinatal period, and gradually decreased by 21 days of age to reach a level that remained constant throughout adult life. The time at which the peak occurred was different in different neural tissues: early in the spinal cord and cerebellum, for example, but late in the tectum and diencephalon. The relative concentration of N-CAM in different neural tissues in the adult was also found to differ: it was high in the olfactory bulb but low in the trigeminal nerve and spinal cord. (2) $\mathrm{E} \rightarrow \mathrm{A}$ conversion of $\mathrm{N}$-CAM was a gradual process, occurring largely in the first three postnatal weeks in the whole brain of the mouse. When different neural regions were examined separately, the conversion rates were found to be different: rapid in the dorsal root ganglia, retina, cerebellum, and spinal cord, but slow in the tectum and diencephalon. (3) $\Lambda$ moderate but definite cephalocaudal maturation gradient was found in the $\mathrm{E} \rightarrow \mathrm{A}$ conversion of the spinal cord and the dorsal root ganglia. There was no detectable conversion gradient detected within portions of the retina and tectum. (4) Differences in antigenic determinants were detected in the N-CAM present in different tissues by the use of monoclonal antibodies. MAb $9 \mathrm{E} 11$ bound N-CAMs present in most brain regions but not $\mathrm{N}$ CAMs in olfactory mucosa, olfactory bulb, and cerebellum;
MAb No. 5 recognized N-CAMs from most brain regions but did not bind N-CAMs from muscle. (5) Different ratios of the three A form bands were detected in some regions of the adult brain. Olfactory mucosa and olfactory bulb primarily contained the $M_{\mathrm{r}}=180,000$ band; spinal cord displayed primarily the $M_{\mathrm{r}}$ $=120,000$ band.

Before considering the biological implications of these findings, several technical constraints deserve mention. Given the histological complexity of the brain, it is clear that the amount and forms of N-CAM determined for a given neural region represent averages of values from tissue containing different amounts and types of neuronal cells and glial cells. In a lysate containing the E form and the three A forms of N-CAM, it is possible that each of these components may be present in only one neuronal type, or only on certain parts of neuronal membranes such as dendrites, growth cones, or synapses. Further examination of N-CAMs with monoclonal antibodies to stain brain sections will be necessary to resolve this issue.

In the quantitation of N-CAM, the differences in N-CAMs demonstrated in this study (e.g., differential binding capacity for MAb 9E11) prompted us to use rabbit polyclonal antibodies instead of monoclonal antibodies to ensure detection of all species of N-CAM. The $\mathrm{E} \rightarrow \mathrm{A}$ conversion of N-CAM added another dimension of complexity. It was impractical to determine standard curves with mixtures of the $\mathrm{E}$ and $\mathrm{A}$ forms of $\mathrm{N}$-CAM that would correspond to each individual age. We therefore used the embryonic form of N-CAM (purified from perinatal whole brain) as the basis of one standard curve used for all ages in this study. Moreover, the purified N-C.AM might have changed conformation with alteration of some antigenic determinants during purification, giving an apparently higher estimation of the amount of N-CAM in lysates. While the absolute values calculated here might therefore have some intrinsic hiases, the relative differences in N-CAM concentration among different ages and regions should nonetheless remain the same.

It is also important to note that, because of the small size of the dissected neural regions, detergent extracts from whole tissue rather than plasma membrane fractions were used in most of these studies. Therefore, in addition to N-CAM on the cell surface, our measurements include N-CAM that is being synthesized or transported in the cytoplasm. Despite this fact, however, when membrane fractions purified from the whole brain by sucrose density gradients were analyzed, the changing profile of concentration of N-CAM followed a similar pattern as that determined with total lysates (Fig. 2). Moreover, immunocytochemical localization of N-CAM revealed that most of the N-CAM is on the cell membrane. These data suggested that the results obtained with total lysates were mainly representative of cell surface N-CAM.

Having considered these technical points, we now turn to the possible mechanism and significance of the alterations of N-CAM found in this study. The change in N-CAM concentration in various neural regions during development could be interpreted in several ways. It might result from changes in the cellular composition of the tissue. For example, the increases of N-CAM concentration around birth could be due to massive outgrowth of neurites or to a differential increase of N-CAM in only some regions of cellular contacts (e.g., the growth cone). Similarly, decreases in the N-CAM concentration could result from the decrease in number of neurites known to occur in development (Purves and Lichtman, 1980), or from the increase of glial cells which could dilute the proportion of neuronal cells. Alternatively, the changes could reflect alterations in the rate of synthesis of N-CAM which might occur during neuronal differentiation. In order to assess the relative contributions of these variables, it will be necessary to carry out quantitative electron microscopic studies to determine whether the amount of N-CAM per unit cell surface area is constant and uniformly 
distributed during development as well as to determine the turnover rates of $\mathrm{N}-\mathrm{CAM}$ in various regions.

The mechanism of $\mathrm{E} \rightarrow \mathrm{A}$ conversion of $\mathrm{N}$-CAM could involve alteration of the pre-existing $\mathrm{E}$ form molecules into the $\mathrm{A}$ forms or replacement of the $\mathrm{E}$ form molecules by newly synthesized A form molecules. These two forms of N-CAM may derive from the same gene product that has undergone different posttranslational processing, either by induction of a sialidase or by repression of a glycosyl transferase at different times. Alternatively, they could be different gene products. In other developmentally regulated proteins, control of expression occurs at different levels. For example, alterations in extrajunctional and junctional acetylcholine receptors are probably due to posttranslational modification (Fambrough, 1979), whereas the difference between fetal and adult hemoglobin is due to a switch in gene expression (Bunn, 1983). Further studies of N-C.AM expression at the transcriptional and translational level are needed to resolve this issue.

It is interesting to note that, in several other contexts, the sialic acid composition in the brain has been reported to change during development. The relative sialic acid content decreases in N-CAM (Chuong and Edelman, 1982; Rothbard et al., 1982), BSP-2 (Finne et al., 1983), D2 (Jørgenson, 1981), as well as in the total neuronal glycoproteins (Margolis et al., 1976). In contrast, most of the sialic acid-rich gangliosides increase in concentration (measured as grams of sialic acid per gram of tissue dry weight) during the 10 to 20 days after birth in mice (Seyfried et al., 1983). There are age-specific changes in neuraminidase activity as well; high aclivity was reported in mouse brains at 3 and 28 days of age (Wille and Trenkner, 1981) and in the synaptosomal fractions of 1-month-old rat (Cruz and Gurd, 1981). These neuraminidase activities might account for the loss of sialic acid from glycoproteins including N-CAM. Although the relationship of these observations is uncertain, it may be of interest that the sialic acid content of different macromolecules changes dramatically during the period when neural connections are being made.

The observed differences in $\mathrm{E} \rightarrow \mathrm{A}$ conversion rates in various neural tissues could result from several possible mechanisms: (1) the onset of $\mathrm{E} \rightarrow \mathrm{A}$ conversion may occur at different times in different regions; (2) once initiated, the rates of the conversion process may vary; or (3) a small population of cells in the region may retain their embryonic characteristics in the adult brain. In general, the known order of ncuronal emergence parallels the order of $\mathrm{E} \rightarrow \mathrm{A}$ conversion and favors the first possibility. However, some regions with slower $\mathrm{E} \rightarrow \mathrm{A}$ conversion, such as hippocampus and olfactory bulb, are reported to contain continuously dividing neurons even in adult animals (Kaplan and Hinds, 1977). If these newly generated neurons can be compared with dividing neurons in the developing embryonic brain, they could account for at least some of the observed slow $\mathrm{E} \rightarrow \mathrm{A}$ conversion in these areas, consistent with the third possibility. Finally, there are regions such as tectum and diencephalon, containing significant amounts of the $\mathrm{E}$ form of N-CAM in the adult brain, for which no clear explanation is yet available.

Within separate neural regions, there is a general tendency for histogenesis to occur in cephalocaudal, ventrodorsal, and lateromedial gradients (Cowan, 1982). The detected $\mathrm{E} \rightarrow \mathrm{A}$ conversion gradients in the spinal cord and dorsal root ganglia are compatible with the finding that the spinal cord matures in a cephalic to caudal direction (Hamburger, 1948; Nornes and Das, 1974). The observed $\mathrm{E} \rightarrow \mathrm{A}$ conversion gradient is not very steep, consistent with the 1-day difference in neuronal birth dates among cervical, thoracic, and lumber spinal cords (Nornes and Das, 1974).

One interesting difference in $\mathrm{E} \rightarrow \mathrm{A}$ conversion rate found in this study was reflected in the discrepancy between the rapid conversion in retina and the slow conversion in optic tectum (Fig. 7). It is conceivable that, because of the strikingly different adhesivity of the $\mathrm{E}$ form and A forms of N-CAM (Hoffman and Edelman, 1983), differences in the timing of $\mathrm{E} \rightarrow \mathrm{A}$ conversion in these two tissues could be used to generate patterns leading to retinotectal maps. This notion prompted us to scarch for topographical distributions of the $\mathrm{E}$ form and $\mathrm{A}$ forms of $\mathrm{N}$-CAM within both tissues. No apparent maturation gradient was detected within either retina or tectum in this study, but we cannot exclude the possibility that a maturation gradient of $\mathrm{E} \rightarrow \mathrm{A}$ conversion indeed exists at a finer level of resolution (e.g., across only a few cells) or over axes different from those used in our dissections. Moreover, current methods do not tell whether the E form of N-CAM in the tectum is actually from the tectal cells or from the neurites of the retinal ganglion cells. Further experiments with application of neuroanatomical techniques, isolation of cell populations, and biosynthetic labeling of ganglion cells will shed further light on this issue.

In addition to the quantitative variation in N-CAM and rates of $\mathrm{E} \rightarrow \mathrm{A}$ conversion, certain important qualitative alterations have also been observed. $\mathrm{F} \rightarrow \mathrm{A}$ conversion in the cerebellum, but not in most other brain regions, was accompanied by the loss of binding of MAb $9 \mathrm{E} 11$. Although the precise chemical nature of the antigenic determinant of MAb $9 \mathrm{E} 11$ is not known, it does not involve sialic acid. It is pertinent to note that MAb 9E11 was obtained after immunizing mice with denatured mouse N-CAM (Chuong et al., 1982). This procedure may have forced the production of monoclonal antibodies that recognize unusual conformations of the antigen. Another monoclonal antibody, Mab No. 5, recognized N-CAM from brain but not from muscle. These data further substantiate the notion that $\mathrm{N}$-CAMs expressed by different tissues may show significant conformational or chemical differences that may ultimately be shown to have functional significance.

Given the possibility that different neuronal types may produce N-CAMs with some modulated differences, it is important to determine whether the three different $\mathrm{A}$ forms are segregated in different neuronal populations. Several tissues indeed showed mainly one of the three A forms. In olfactory mucosa, for example, the $M_{\mathrm{r}}=180,000$ band was dominant (Fig. 10). Olfactory mucosa originates from somatic ectoderm (the nasal placode) instead of neuroectoderm and it is composed of only one neuronal cell type (the olfactory neuron) which undergoes constant turnover throughout adult life (Graziadei and Graziadei, 1978). It is not yet clear whether any of these special characteristics of olfactory mucosa is the basis for the dominance of the $M_{\mathrm{r}}=180,000$ component. In the spinal cord, the $M_{\mathrm{r}}=120,000$ band was dominant. This result is in agreement with the studies on BSP-2 (Rougon et al., 1982), now identified as N-CAM with our antibodies (C. Goridis, personal communication). The structural basis and functional significance of the three A form components and the different antigenic determinants as recognized by MAb $9 \mathrm{E} 11$ and MAb No. 5 are not yet known. This study, however, provides a basis for future analysis which will require fractionation of each $\mathrm{A}$ form and $\mathrm{a}$ study of its functional differences in adhesivity.

In general, variations in the time schedules of quantitative and qualitative changes of N-CAM in different regions appeared to correlate with differences in the schedules of neuronal maturation and formation of neurite connections in these regions (for a review, see Jacobson, 1978). In each of the neural tissues examined, the emergence of neurons (defined by the last mitosis) was followed by the peak in relative N-CAM concentration, which was in turn followed by $\mathrm{E} \rightarrow \mathrm{A}$ conversion, both events occurring at intervals of 5 to 10 days. It is attractive to postulate that, just before neurons in certain regions are ready to make connections, they first express large amounts of the $\mathrm{E}$ form of N-CAM. The adhesive force between these $\mathrm{E}$ 
forms of N-CAMs may be enough to hold neurites together, while still allowing the relative movement of neurites that is necessary to search for new targets or to retract from supernumerary contacts (Brown et al., 1976; Lichtman and Purves, 1982). In this view, $\mathrm{E} \rightarrow \mathrm{A}$ conversion would occur during or after the period of competition and selection among the early neural connections. The conversion would result in a stronger adhesive force between the A forms of N-CAM which would then stabilize the selected neurite connections. For example, a multiple innervation pattern between the motor neuron and muscle changes into a one-to-one innervation pattern between 7 and 14 days of age (Korneliussen and Jansen, 1976), just when most of the $\mathrm{E} \rightarrow \mathrm{A}$ conversion occurs in the spinal cord. This hypothesis that $\mathrm{E} \rightarrow \Lambda$ conversion of $\mathrm{N}$-CAM is related mainly to the stabilization of neuronal connections is further supported by the correlation between connectional disorders and failure of $\mathrm{E} \rightarrow \mathrm{A}$ conversion of $\mathrm{N}$-CAM in the staggerer mouse mutants (Edelman and Chuong, 1982).

This study has established that quantitative and qualitative alterations in N-CAM occur in various neural regions at different developmental times. Together with the finding that different concentrations and forms of N-CAM can result in different binding efficacies (Hoffman and Edelman, 1983), the data suggest the existence of complex patterns of temporal and spatial changes in the adhesion strength mediated by N-CAM in the developing brain. Such differences in adhesivity could serve as major dynamic cues in the establishment of specific neural connections. Recently, another cell adhesion molecule, $\mathrm{Ng}$-CAM, present on neurons and important in neuron-glia interactions, has been identified in our laboratory (Grumet et al., 1984). Given several different possible surface modulation mechanisms (Edelman, 1976, 1983), the interplay between these two molecules alone could generate enormous complexity during neural morphogenesis. In future studies, it will be important to compare the expression of these two CAMs and to correlate the different amounts and different $\mathrm{E} \rightarrow \mathrm{A}$ conversion rates of $\mathrm{N}$-CAM with the physiological events (cell movements, cell contacts, cytodifferentiations, regression of the supernumerary innervations, synaptogenesis) that occur during the same period in each neural region. It will also be important to test whether pathological events (nerve regeneration, sensory deprivation, etc.) could lead to modulation of the amounts or forms of N-CAM. Such studies should enhance our understanding of the in vivo function of N-CAM as well as of the exquisite order that emerges during the development of the brain.

\section{References}

Brackenbury, R., J. -P. Thiery, U. Rutishauser, and G. M. Edelman (1977) Adhesion among neural cells of the chick embryo. I. An immunological assay for molecules involved in cell-cell binding. J. Biol. Chem. 252: 6835-6840.

Bradford, M. (1976) A rapid and sensitive method for the quantitation of microgram quantities of protein utilizing the principle of proteindye binding. Anal. Biochem. 72: 248-254.

Brown, M. C., J. K. S. Jansen, and D. Van Essen (1976) Polyneuronal innervation of skeletal muscle in newborn rats and its elimination during maturation. J. Physiol. (Lond.) 261: 387-422.

Bunn, H. F. (1983) Anemia. In Harrison's Principle of Internal Medicine, Ed. 10, R. G. Petersdorf, R. D. Adams, E. Braunswald, K. J. Isselbaum, J. B. Martin, and J. D. Wilson, eds., pp. 282-292, McGraw-Hill, New York.

Buskirk, D. R., J. -P. Thiery, U. Rutishauser, and G. M. Edelman (1980) Antibodies to a neural cell adhesion molecule disrupt histogenesis in cultured chicken retinae. Nature 285: 488-489.

Chuong, C. -M., D. A. McClain, P. Streit, and G. M. Edelman (1982) Neural cell adhesion molecules in rodent brains isolated by monoclonal antibodies with cross-species reactivity. Proc. Natl. Acad. Sci. U. S. A. 79 : $4324-4328$.

Cowan, W. M. (1982) The development of the vertebrate central nervous system: An overview. In Development in Nervous System, D. R. Garrod, ed. pp. 3-33, Cambridge University Press, Cambridge, England.

Cruz, T. F., and J. W. Gurd (1981) The effect of development on activity, specificity and endogenous substrates of synaptic membrane sialidase. Biochim. Biophys. Acta 675: 201-208.

Edelman, G. M. (1976) Surface modulation in cell recognition and cell growth. Science 192: 218-226.

Edelman, G. M. (1983) Cell adhesion molecules. Science 219: 450-457.

Edelman, G., M., and C. -M. Chuong (1982) Embryonic to adult conversion of neural cell adhesion molecules in normal and staggerer mice. Proc. Natl. Acad. Sci. U. S. A. 79: 7036-7040.

Edelman, G. M., W. J. Gallin, A. Delouvee, B. A. Cunningham, and J. -P. Thiery (1983)Early epochal maps of two different cell adhesion molecules. Proc. Natl. Acad. Sci. U. S. A. 80: 4384-4388.

Fambrough, D. M. (1979) Control of acetylcholine receptors in skeletal muscle. Physiol. Rev. 59: 165-227.

Finne, J., U. Finne, H. Deagostine-Bazin, and C. Goridis (1983) Occurrence of 2-8 linked polysialosyl units in a neural cell adhesion molecule. Biochem. Biophys. Res. Commun. 112:482-487.

Graziadei, P. P. C., and G. A. M. Graziadei (1978) The olfactory system: A model for the study of neurogenesis and axonal regeneration in mammals. In Neuronal Plasticity, C. W. Cotman, ed., pp. 131-153, Raven Press, New York.

Grumet, M., U. Rutishauser, and G. M. Edelman (1982) Neural cell adhesion molecule is on embryonic muscle cells and mediates adhesion to nerve cells in vitro. Nature (Lond.) 25: 693-695.

Grumet, M., S. Hoffman, and G. M. Edelman (1984) Two antigenically related neuronal CAM's of different specificities mediate neuronneuron and neuron-glia adhesion. Proc. Natl. Acad. Sci. U. S. A. 81: $267-271$.

Hamburger, V. (1948) The mitotic patterns in the spinal cord of the chicken embryo and their relation to histogenetic processes. J. Comp. Neurol. 88: 221 284.

Hoffman, S., and G. M. Edelman (1983) Kinetics of homophilic binding by embryonic and adult forms of the neural cell adhesion molecule. Proc. Natl. Acad. Sci. U. S. A. 80: 5762-5766.

Hoffman, S., B. C. Sorkin, P. C. White, R. Brackenbury, R. Mailhammer, U. Rutishauser, B. A. Cunningham, and G. Edelman (1982) Chemical characterization of a neural cell adhesion molecule purified from embryonic brain membranes. J. Biol. Chem. 257: 7720-7729.

Jacobson, M. (1978) Development Neurobiology, Ed. 2, Plenum Press, New York.

J $\phi$ rgensen, O. S. (1981) Neuronal membrane D2-protein during rat brain ontogeny. J. Neurochem. 37: 939-946.

Kaplan, M. S., and J. W. Hinds (1977) Neurogenesis in the adult rat: Electron microscopic analysis of light radioautography. Science 197: 1092-1094.

Korneliussen, H., and J. K. S. Jansen (1976) Morphological aspects of the elimination of polyneuronal innervation of skeletal muscle fibers in newborn rats. J. Neurocytol. 5: 591-604.

Lichtman, J. W., and D. Purves (1982) Regulation of the number of axons that innnervate target cells. In Development in the Nervous System, D. R. Garrod, ed., pp. 233-243, Cambridge University Press, Cambridge, England.

Margolis, R. K., C. Preti, D. Lai, and R. U. Margolis (1976) Developmental changes in brain glycoproteins. Brain Res. 112: 363-369.

Nornes, H. O., and G. D. Das (1974) Temporal pattern of neurogenesis in spinal cord of rat. I. An autoradiographic study-Time and sites of origin and migration and settling pattern of neuroblasts. Brain Res. 73: 121-138.

Purves, D., and J. W. Lichtman (1980) Elimination of synapses in the developing nervous system. Science 210: 153-157.

Rothbard, J. B., R. Brackenbury,B. A. Cunningham, and G. M. Edelman (1982) Differences in carbohydrate structures of neural cell adhesion molecules from adult and embryonic chicken brains. J. Biol. Chem. 251: 11064-11069.

Rougon, G., H. Deagostini-Bazin, M. Hirn, and C. Goridis (1982) Tissue and developmental stage-specific form of a neural cell surface antigen linked to differences in glycosylation of a common polypeptide. EMBO J. 1: 1239-1244.

Rutishauser, U., W. E. Gall, and G. M. Edelman (1978) Adhesion among neural cells of the chick embryo. IV. Role of the cell surface molecule CAM in the formation of neurite bundles in cultures of spinal ganglia. J. Cell Biol. 79: 382-393. 
Seyfried, T. N., N. Miyazawa, and R. K. Yu (1983) Cellular localization of gangliosides in the developing mouse cerebellum. I. Analysis using the weaver mutant. J. Neurochem. 41: 491-505.

Sidman, R. L., J. B. Angevine, Jr., and E. T. Pierce (1971) Atlas of the Mouse Brain and Spinal Cord, Harvard University Press, Cambridge, MA.

Takeichi, M. (1977) Functional correlation between cell adhesive properties and some cell surface proteins. J. Cell Biol. 75: 464-474.

Theiler, K. (1972) The House Mouse, Springer-Verlag, New York.

Thiery, J. -P., J. -L. Duband, U. Rutishauser, and G. M. Edelman
(1982) Cell adhesion molecules in early chicken embryogenesis. Proc. Natl. Acad. Sci. U. S. A. 79: 6737-6741.

Towbin, H., T. Staehelin, and J. Gordon (1979) Electrophoretic transfer of proteins from polyacrylamide gels to nitrocellulose sheets: Procedure and some applications. Proc. Natl. Acad. Sci. U. S. A. 76: 4350-4354.

Willie, W., and E. Trenkner (1981) Changes in particular neuraminidase activity during normal and staggerer mutant mouse development. J. Neurochem. 37: 443-446. 